\title{
The Econometric Submodels of the Energy Policy Socioeconomic Impact Model (EPSIM)
}

by J.G. Butler and D.A. Poyer

Energy Systems Division,

Argonne National Laboratory, 9700 South Cass Avenue, Argonne, Illinois 60439

April 1994

Work sponsored by United States Department of Energy, Office of Economic Impact and Diversity 


\section{CONTENTS}

ACKNOWLEDGMENTS $\ldots \ldots \ldots \ldots \ldots \ldots \ldots \ldots \ldots \ldots \ldots \ldots$

AVAILABILITY OF COMPUTER SOFTWARE $\ldots \ldots \ldots \ldots \ldots \ldots \ldots \ldots \ldots$ vi

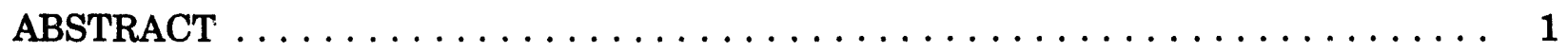

1 INTRODUCTION $\ldots \ldots \ldots \ldots \ldots \ldots \ldots \ldots \ldots \ldots \ldots \ldots \ldots \ldots \ldots \ldots$

2 EPSIM TECHNICAL SPECIFICATIONS $\ldots \ldots \ldots \ldots \ldots \ldots \ldots$

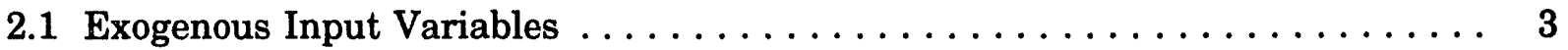

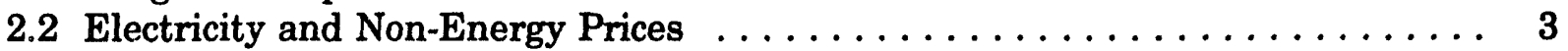

2.3 Non-Electric Energy Price $\ldots \ldots \ldots \ldots \ldots \ldots \ldots \ldots \ldots \ldots \ldots \ldots$

2.4 Household Expenditures and Discretionary Expenditure Parameters . . . . . . 3

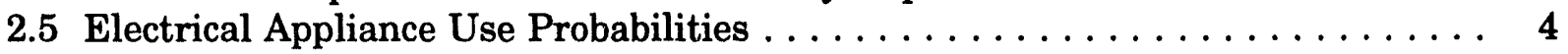

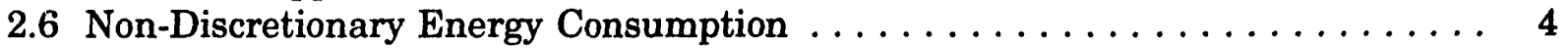

2.7 Electricity and Non-Electric Energy Consumption and Expenditures $\ldots \ldots \ldots 4$

2.8 Parameter Estimation and Model Validation $\ldots \ldots \ldots \ldots \ldots \ldots$

3 MANIPULATING THE BASIC MODEL FOR UTILITY RATE DESIGN

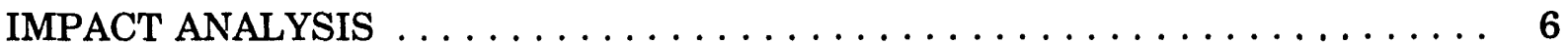

4 MANIPULATING THE BASIC MODEL FOR DEMAND-SIDE

MANAGEMENT PROGRAM ANALYSIS $\ldots \ldots \ldots \ldots \ldots \ldots \ldots \ldots$

5 EXAMINING EPSIM RESPONSE CHARACTERISTICS THROUGH ANALYSIS OF ENERGY PRICE ELASTICITIES $\ldots \ldots \ldots \ldots \ldots \ldots \ldots \ldots \ldots$

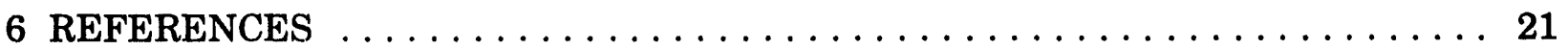

APPENDIX A: EPSIM Technical Specification with

Representative Values . . . . . . . . . . . . . . 23

APPENDIX B: EPSIM Version 1.0 Source Code

and Parameter Values ...................... 31

\section{FIGURES}

1 Electricity Consumption Residuals $\ldots \ldots \ldots \ldots \ldots \ldots \ldots$

2 Price Elasticities and Appliance Shares by Ethnicity and Poverty . . . . . . . 9

3 Price Elasticities and Appliance Shares by House Type . . . . . . . . . . . . . 12 


\section{FIGURES (Cont.)}

4 Elasticities and Appliance Shares by House Vintage $\ldots \ldots \ldots \ldots \ldots$

5 Price Elasticities and Appliance Shares by Appliance Use . . . . . . . . . . . . . 18 


\section{ACKNOWLEDGMENTS}

The development of the Energy Policy Socioeconomic Impact Model (EPSIM) was sponsored by the U.S. Department of Energy, Office of Economic Impact and Diversity, under contract W-31-109-Eng-38.

Mathcad is a trademark of Mathsoft, Inc. FoxPro is a trademark of the Microsoft Corporation. IBM is a trademark of the International Business Machines Corporation. SAS is a trademark of SAS Institute, Inc. 


\section{AVAILABILITY OF COMPUTER SOFTWARE}

Electronic copies of the software described in this publication will be distributed with appropriate restrictions by:

Energy Science and Technology Software Center

P.O. Box 1020

Oak Ridge, TN 37831-1020

For information regarding requests for software, call (615) 576-2606. 


\title{
THE ECONOMETRIC SUBMODELS OF THE \\ ENERGY POLICY SOCIOECONOMIC \\ IMPACT MODEL (EPSIM)
}

by

\author{
J.G. Butler and D.A. Poyer
}

\begin{abstract}
The Energy Policy Socioeconomic Impact Model (EPSIM) is an econometric simulation model that runs on IBM-compatible personal computers. It can be used to assess the economic impact of energy policies and programs, such as utility rate designs and demand-side management programs, on various population groups, such as minority and low-income households. The econometric submodels that constitute the internal structure of EPSIM are described in detail.
\end{abstract}

\section{INTRODUCTION}

The Energy Policy Socioeconomic Impact Model (EPSIM) is an econometric simulation model developed by the Socioeconomic Research and Analysis Program, Energy Systems Division, Argonne National Laboratory, under the sponsorship of the Office of Economic Impact and Diversity, U.S. Department of Energy (DOE). The purpose of EPSIM is to assess the economic impact of energy policies and programs, such as utility rate designs and demand-side management programs, on various population groups, such as minority and low-income households. A version of the model that runs on IBM-compatible personal computers is available through the Energy Science and Technology Software Center, Oak Ridge, Tennessee. The user interface for that version is described in the user's guide (Butler and Poyer 1993) that accompanies the software.

This report describes the econometric submodels that constitute the heart of EPSIM. In addition, this report describes the structure of the EPSIM model in detail, starting with representative values for the exogenous variables and working through to the output results. It also develops expressions for calculating the electricity price elasticities for individual households. The calculation of elasticities is not explicitly part of the EPSIM structure, but it reveals how EPSIM generates different responses to energy price changes for households with different demographic characteristics.

Appendix A contains a complete specification of the EPSIM econometric submodels, except for the values of the parameter vectors. It was prepared with Mathcad 4.0 mathematical software (Mathsoft 1993). When run with the Mathcad host program, the calculations presented in Appendix A are a working model of the mathematical equations and 
expressions contained in EPSIM. The ":=" symbol denotes variable and function definitions, while the " $=$ " symbol displays the current value of the specified variable or expression. Before any variable can be evaluated (or used in an expression to be evaluated), it must have appeared on the left side of a previous Mathcad definition. A Mathcad document operates in a manner similar to a spreadsheet template, performing its calculations in sequence from top to bottom and from left to right. In EPSIM Version 1.0, the calculations described in Appendix A are performed on each of the 1,606 households that make up the Midwest sample of the 1987 Residential Energy Consumption Survey (RECS) (DOE 1989). 


\section{EPSIM TECHNICAL SPECIFICATIONS}

\subsection{EXOGENOUS INPUT VARIABLES}

EPSIM requires the following household information as exogenous input data: house vintage (year built); house type (single-family, two to four units multifamily, five or more units multifamily, mobile home); metropolitan location (inner city, suburban/rural); heated house area (square feet); heating degree-days; cooling degree-days; price of electricity; age, gender, and ethnicity of household head; and household size, income, and poverty status. In EPSIM Version 1.0, this information is obtained from the 1987 RECS Midwest sample (DOE 1989). This information is made available to the model equations through the vectors $X_{s}$ and Xe of explanatory variables and expressions.

\subsection{ELECTRICITY AND NON-ENERGY PRICES}

The composite price of non-energy goods $P_{c}$ was set equal to 1.44 , the level of the consumer price index $(1979=1.00)$ in 1987 . The electrical appliance share models use the exogenously supplied electricity price $P_{e l}$. For the EPSIM households taken from the 1987 RECS, this price is obtained by dividing the total reported electricity expenditures by the total reported electricity consumption. The equations for electricity and total energy demand specify an endogenously determined two-part electricity tariff consisting of a fixed customer charge $M_{e l c}$ plus a consumption-related energy charge $P_{e l c}$. The values of $M_{e l c}$ and $P_{e l c}$ were estimated to be $\$ 86.50 / y r$ and $\$ 18.66$ per million Btu's, respectively. These values were estimated by using non-linear regression techniques and the combined Midwest samples of the 1981, 1982, 1984, and 1987 RECS samples (DOE 1983, 1985, 1987, 1989).

\subsection{NON-ELECTRIC ENERGY PRICE}

The non-electric energy price $P_{n e l}$ was estimated separately from the combined RECS samples by using the demographic variables contained in vector $\mathbf{X s}$ as instrumental variables. The adjustment variable $m r$ (Mill's ratio) is estimated from a probit model described by Maddala (1983) that compensates for the fact that the sample from which the non-electric energy price model was estimated excludes all-electric households. An important method by which EPSIM generates differential behavioral responses to energy price changes is to allow $P_{n e l}$ to vary on demographic factors.

\subsection{HOUSEHOLD EXPENDITURES AIND DISCRETIONARY EXPENDITURE PARAMETERS}

EPSIM budgets fixed portions $\beta_{e l}$ and $\left(\beta_{e}-\beta_{e l}\right)$ of discretionary household expenditures $\left(M-P_{c} * \gamma_{c}\right)$ to electricity and non-electric energy consumption. The non-linear "life-cycle" submodel for household expenditures $M$ uses household income and size as well as ethnicity and age of household head as independent variables. This submodel was 
specified and estimated on the basis of data from the Consumer Expenditure Survey of 1989 (U.S. Department of Labor 1991). This submodel also generates non-discretionary, non-energy consumption $\gamma_{c}$ as a by-product.

\subsection{ELECTRICAL APPLIANCE USE PROBABILITIES}

EPSIM uses logit models to estimate the probabilities of a household's use of electric space heating, water heating, cooking, and air conditioning equipment. These probabilities, or shares, which depend on the vector $\mathrm{X}_{\mathbf{s}}$ of demographic variables and the $P_{e l} / P_{n e l}$ price ratio $\left(\boldsymbol{P}_{e l} / \boldsymbol{P}_{c}\right.$ for air conditioning), are major determinants of a household's non-discretionary electric and non-electric energy consumption and responses to price changes. Indeed, EPSIM generates a household's response to price changes primarily by altering the probabilities of the use of major electrical appliances. Separate share models were estimated for black households to correct for observed overestimates of electric appliance use obtained from the all-households share models. While the consumption estimates and elasticities obtained from these two share models may differ substantially for individual households, these differences appear to balance out within the black sample. The use of either share model reveals significant differences between black and non-black households with respect to energy consumption and price elasticities.

\subsection{NON-DISCRETIONARY ENERGY CONSUMPTION}

Non-discretionary electricity consumption $\gamma_{e l}$ is defined as the dot product of the vector $\mathrm{Xe}$ of explanatory variable expressions and the vector gl of parameters. Non-discretionary, non-electric energy consumption $\gamma_{\text {nel }}$ is defined indirectly as the dot product of $\mathrm{Xe}$ and the vector ge of parameters. The substitutability between electric and non-electric energy is captured by the dependence of both $\gamma_{e l}$ and $\gamma_{\text {nel }}$ on the probabilities of electric appliance use, which, in turn, depend on the price ratio $P_{e l} / P_{n e l}\left(P_{e l} / P_{c}\right.$ for air conditioning).

\subsection{ELECTRICITY AND NON-ELECTRIC ENERGY CONSUMPTION AND EXPENDITURES}

The final step in EPSIM is to derive electricity consumption $Q_{e l}$, non-electric energy consumption $Q_{n e l}$, and average energy price $P_{e l}$ through the simultaneous solution of the energy demand, electricity demand, and average energy price equations shown in Appendix A. The demand equation system solves for total energy consumption $\boldsymbol{Q}_{e}$ and electricity consumption $Q_{e l}$. The value of $Q_{r e l}$ is calculated as the difference between $Q_{e}$ and

$Q_{e l}$. Expenditures on electric and non-electric energy are calculated as simple linear functions of consumption quantities and prices. In the case of electricity, the customer charge $M_{e l c}$ is added to the product of $P_{e l c}$ and $Q_{e l}$ to obtain total electricity expenditures $M_{e l}$. 


\subsection{PARAMETER ESTIMATION AND MODEL VALIDATION}

Values for the 270 parameters used in EPSIM Version 1.0 were estimated by using the MODEL procedure of SAS/ETS Version 6.04 for IBM-compatible personal computers (SAS Institute 1988). These values, along with the FoxPro source code that implements the econometric submodels described in this report, are given in Appendix B. One way to check the validity of the estimated model is to plot the residuals between the observed values for electricity and non-electric energy consumption and the values estimated by EPSIM. Figure 1 plots the electricity residuals. Ideally, these residuals would be distributed normally around a mean value of zero. The cumulative plot in Figure 1 shows that this ideal is nearly achieved. The distribution is only slightly skewed to the right, with little apparent bias.

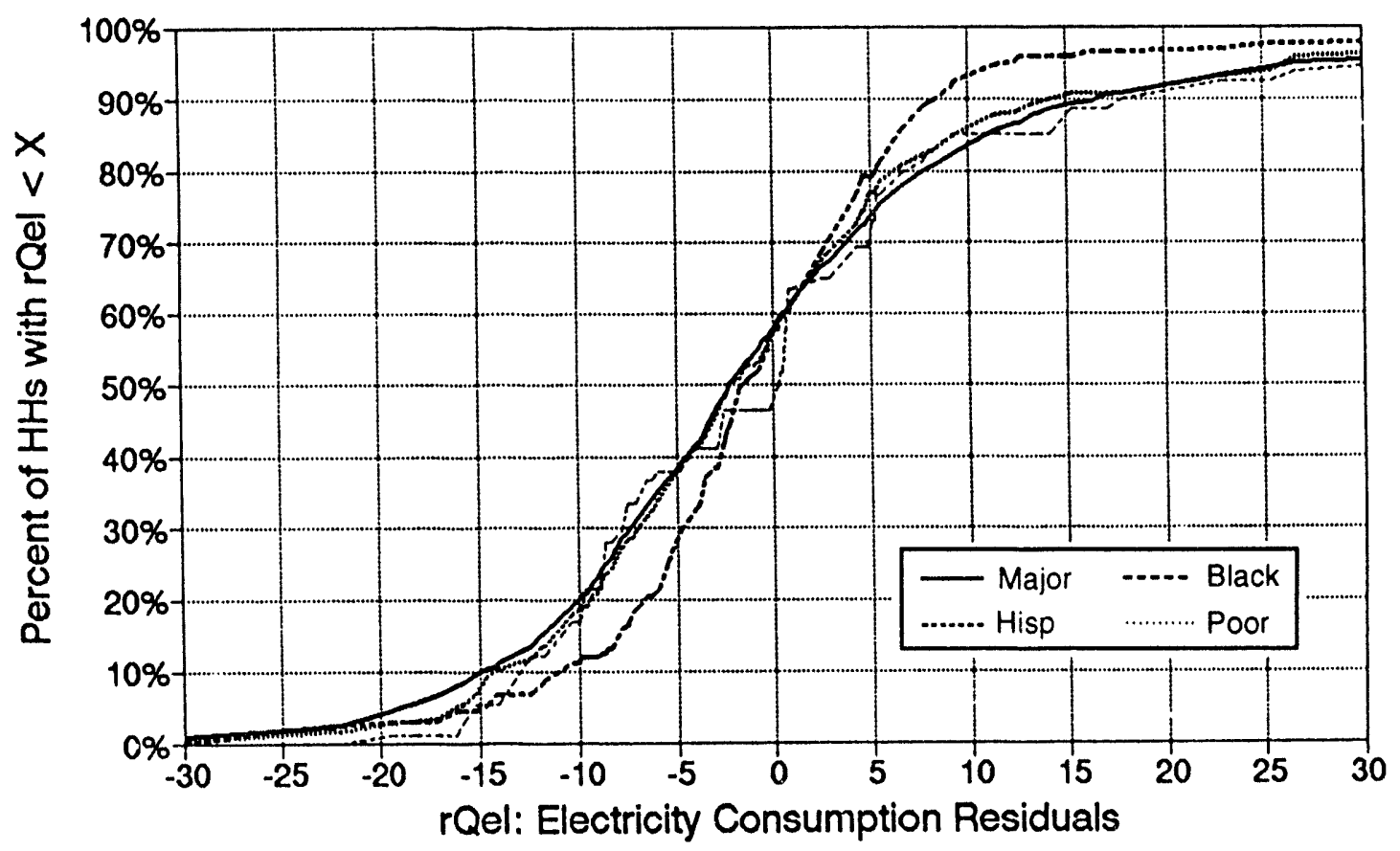

FIGURE 1 Electricity Consumption Residuals (observed compared with estimated; HHs $=$ households) 


\section{MANIPULATING THE BASIC MODEL FOR UTILITY RATE DESIGN IMPACT ANALYSIS}

EPSIM Version 1.0 provides an interface module (URD) through which users can manipulate the basic model to analyze the differential impacts of various two-part electricity tariff designs on minority and low-ıncome households. The analytical facilities provided by URD are described in detail in the EPSIM user's guide (Butler and Poyer 1993). The URD module uses the parameter values for $P_{e l c}$ and $M_{e l c}$ that were estimated from the combined RECS samples for its base case. The user can specify alternative values for these parameters for the policy case. The URD module then multiplies the exogenous electricity price $P_{e l}$ by an amount proportional to the change in $P_{e l c}$ and outputs the cumulative distributions of expenditure differences between the base and policy cases by population group. 


\section{MANIPULATING THE BASIC MODEL FOR DEMAND-SIDE MANAGEMENT PROGRAM ANALYSIS}

EPSIM Version 1.0 also provides an interface module (DSM) through which users can rnanipulate the basic model to analyze the differential impacts of various demand-side management programs. The use of EPSIM in this policy context requires extension of the basic model by the introduction of the concept of the energy service ratio (ESR). The ESR approach views energy as an input to technological processes that generate as output household services, such as heated space and water, illumination, cooked meals, and so on. The ESR is defined as the ratio between a given quantity of service output and the quantity of energy input required to produce that output. An increase in the efficiency of energy use in producing services reduces the implicit price to consumers of these end-use services. Since we are interested only in projecting consumer responses to changes in efficiency, it is not necessary to define explicitly units of consumption for the end-use services. An ESR of unity is specified for the base case, and the ESR for the policy case is derived as unity minus the expected change in efficiency resulting from application of the proposed demand-side management measure.

For example, a demand-side management measure that improves efficiency by $15 \%$ would have an associated ESR of 0.85 (1 - [15/100]). Setting the ESR to unity for the base case equates the price and demand for the end-use service with the price and demand for the energy input. For a specified policy case ESR, the implicit new price $P_{s}$ of the end-use service is calculated as the product of the ESR and the old energy price (either $P_{e l}$ or $P_{n e l}$ ). The value $P_{s}$ is then substituted for $P_{e l}$ or $P_{n e l}$ in the basic model, and a new consumption quantity is calculated. This new consumption quantity $Q_{s}$ represents units of end-use service demanded. To convert $Q_{s}$ back into energy units demanded $\left(Q_{e l}\right.$ or $\left.Q_{n c l}\right), Q_{s}$ is multiplied by ESR. The Oak Ridge National Laboratory Residential Energy Consumption Model uses a similar ESR approach, as described by Cowing and McFadden (1984). The use of the ESR concept in demand-side management program modeling is also discussed by Khazzoom (1986). 


\section{EXAMINING EPSIM RESPONSE CHARACTERISTICS THROUGH ANAL YSIS OF ENERGY PRICE ELASTICITIES}

Appendix A contains analytical expressions for calculating electricity and non-electric energy own-price elasticities for individual households. These expressions were obtained by differentiating the electricity and total energy demand equations with respect to $P_{e l}, P_{e l c}$, and $P_{n e l}$. Figures 2a, 3a, 4a, and 5a plot the cumulative distributions of electricity price elasticities calculated from these expressions for the EPSIM sample households for various categorization schemes. Figures $2 \mathrm{~b}, 3 \mathrm{~b}, 4 \mathrm{~b}$, and $5 \mathrm{~b}$ plot non-electric price elasticities. Figure 2 categorizes the households by ethnicity and poverty level, Figure 3 by house type, Figure 4 by house vintage, and Figure 5 by observed electric appliance use. The categories in Figures 2 and 5 are not mutually exclusive. For example, a household categorized as majority could also be categorized as poor. A household that uses electricity for space heating can (and probably does) also use electricity for air conditioning, and so on. Figures 2 through 5 are based on the separate appliance share models (Model B) for black households. In addition to plotting the cumulative distributions of elasticities, Figures 2 through 5 also contain distributions of the electrical appliance shares (probabilities) for the respective categorization schemes.

Clearly, house type and vintage, heated area, and climate are important determinants of elasticity differences among different households. Differences in the way ethnicity and poverty groups are distributed across these determining factors result in the group differences revealed in Figure 2. Figure 2a suggests that only $38 \%$ of black households would spend more on electricity $\left(-E_{e l}>1\right)$ as a result of an electricity price decrease, compared with $48 \%$ of Hispanic households, $53 \%$ of poor households, and $68 \%$ of majority (non-black, non-Hispanic) households. The median electricity price elasticity is -0.76 for black households, -1.03 for poor households, -0.96 for Hispanic households, and -1.15 for majority households.

As for non-electric energy own-price elasticity, Figure $2 b$ suggests that fewer than $5 \%$ of black households would spend more on non-electric energy $\left(-E_{n e l}>1\right)$ as a result of a price decrease, compared with $19 \%$ of poor households and $31 \%$ of majority households. The median non-electric elasticity is less than -0.2 for black households, less than -0.6 for poor and Hispanic households, and about -0.7 for majority households. 


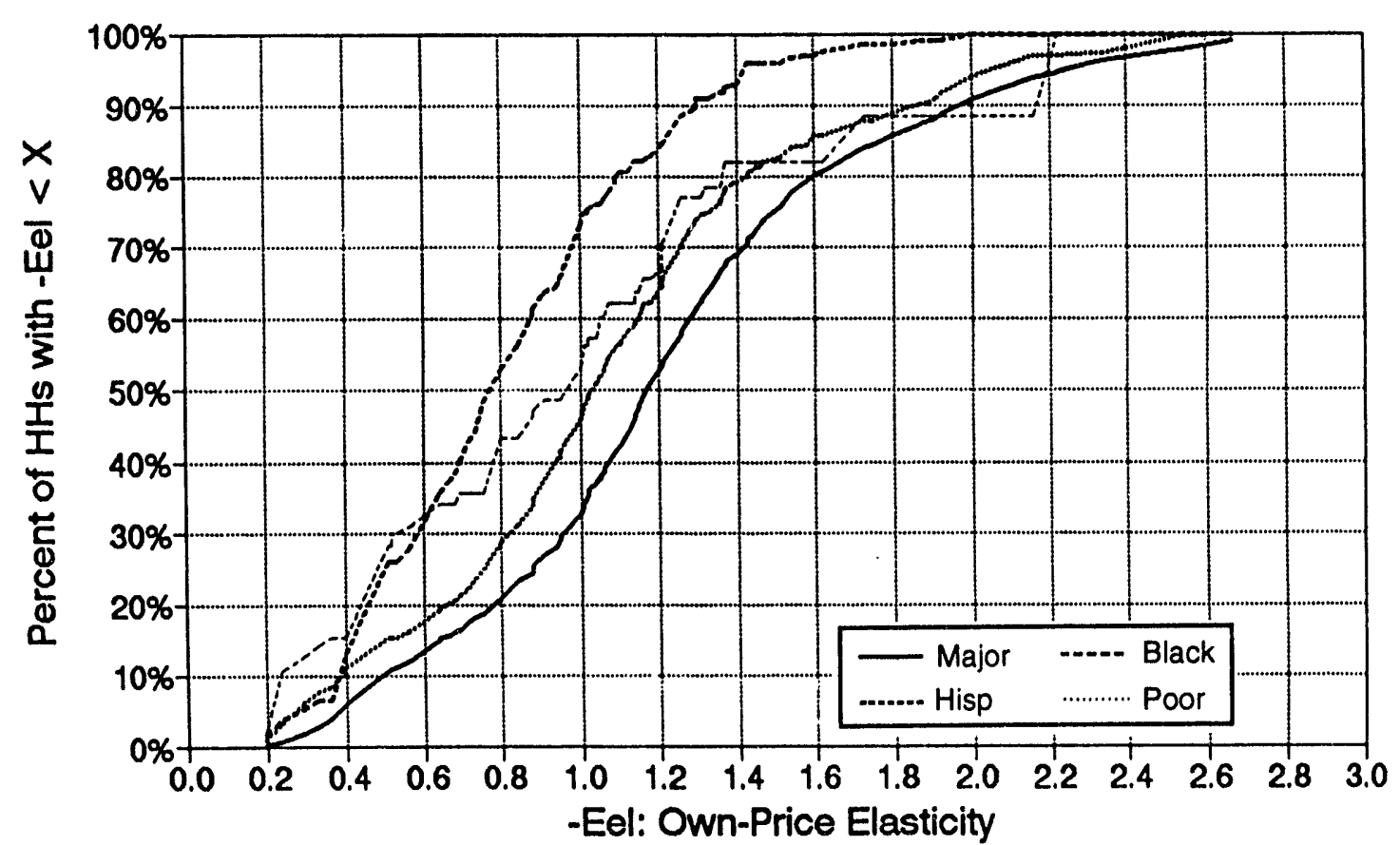

a. Electricity Price Elasticity by Ethnicity and Poverty

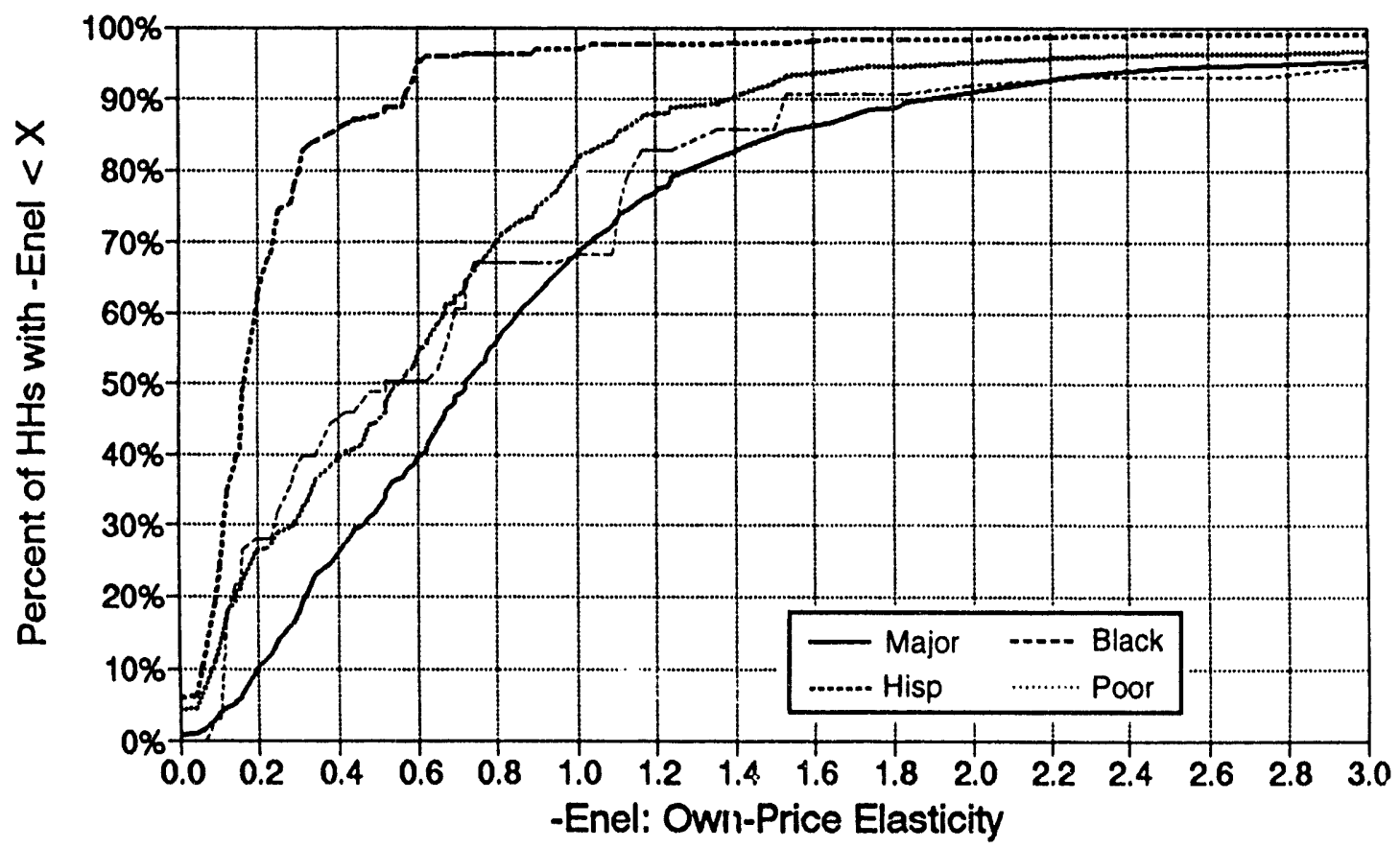

b. Non-Electric Energy Price Elasticity by Ethnicity and Poverty 


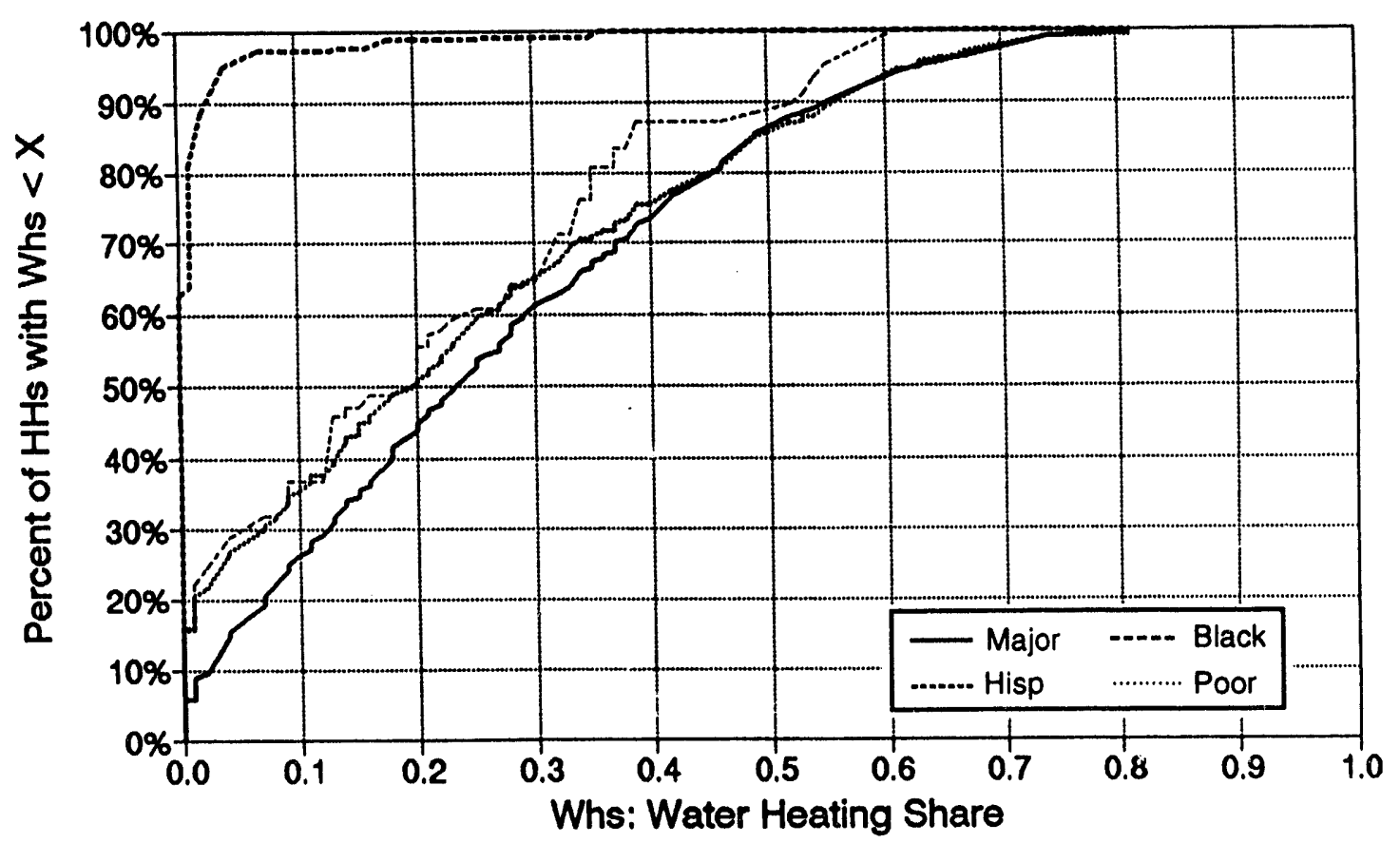

c. Electric Water Heating Share by Ethnicity and Poverty

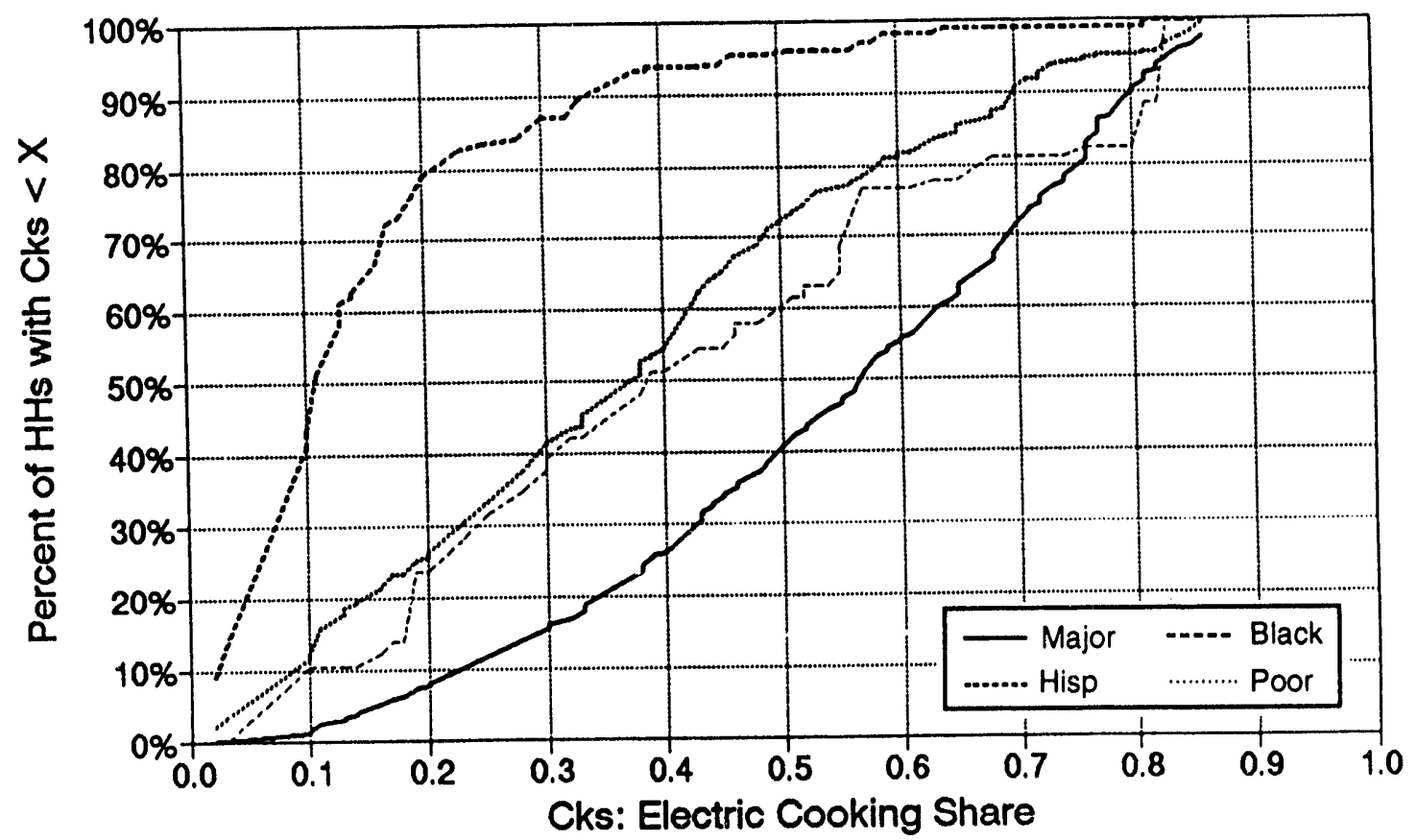

d. Electric Cooking Share by Ethnicity and Poverty

FIGURE 2 (Cont.) 


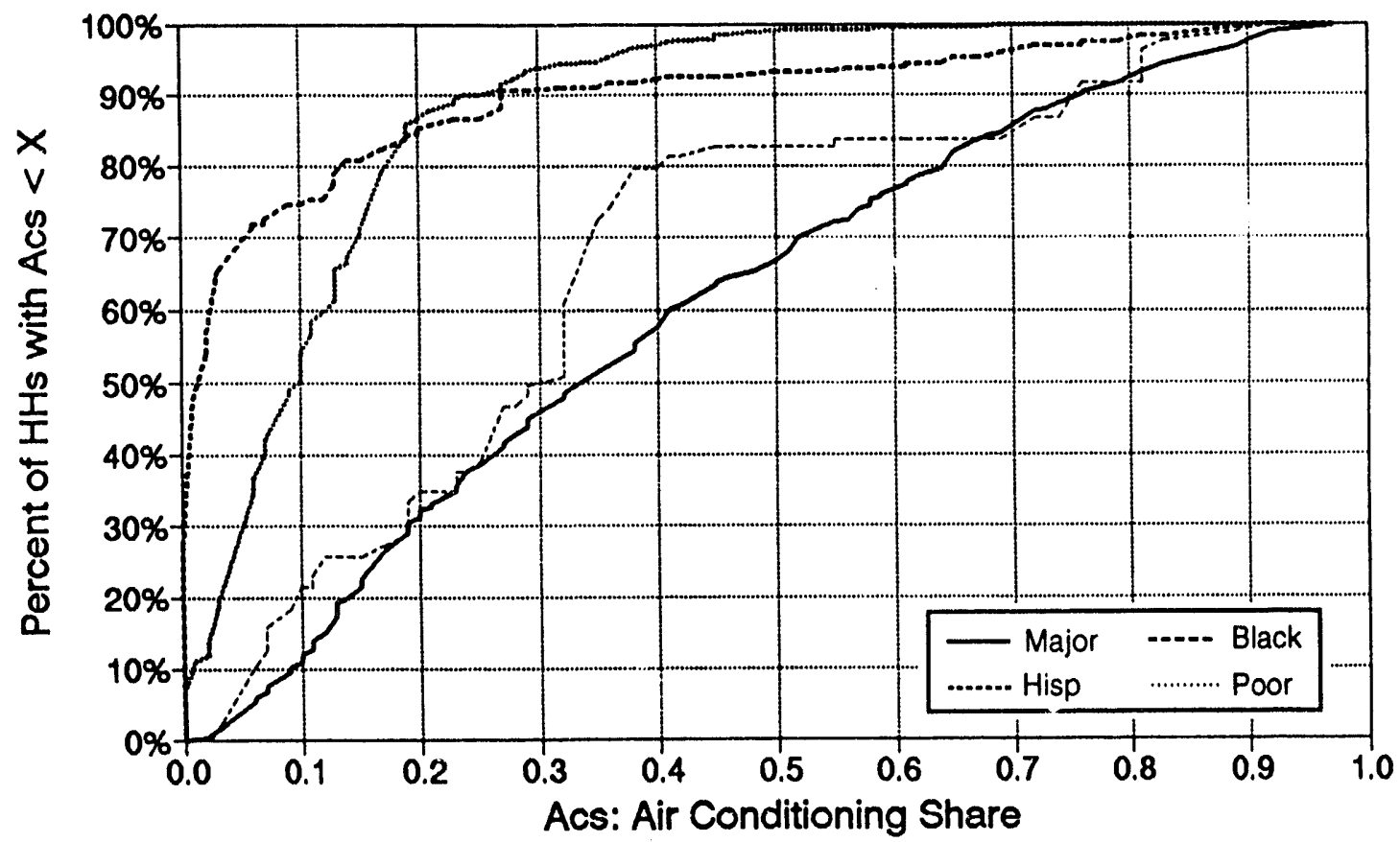

e. Air Conditioning Share by Ethnicity and Poverty

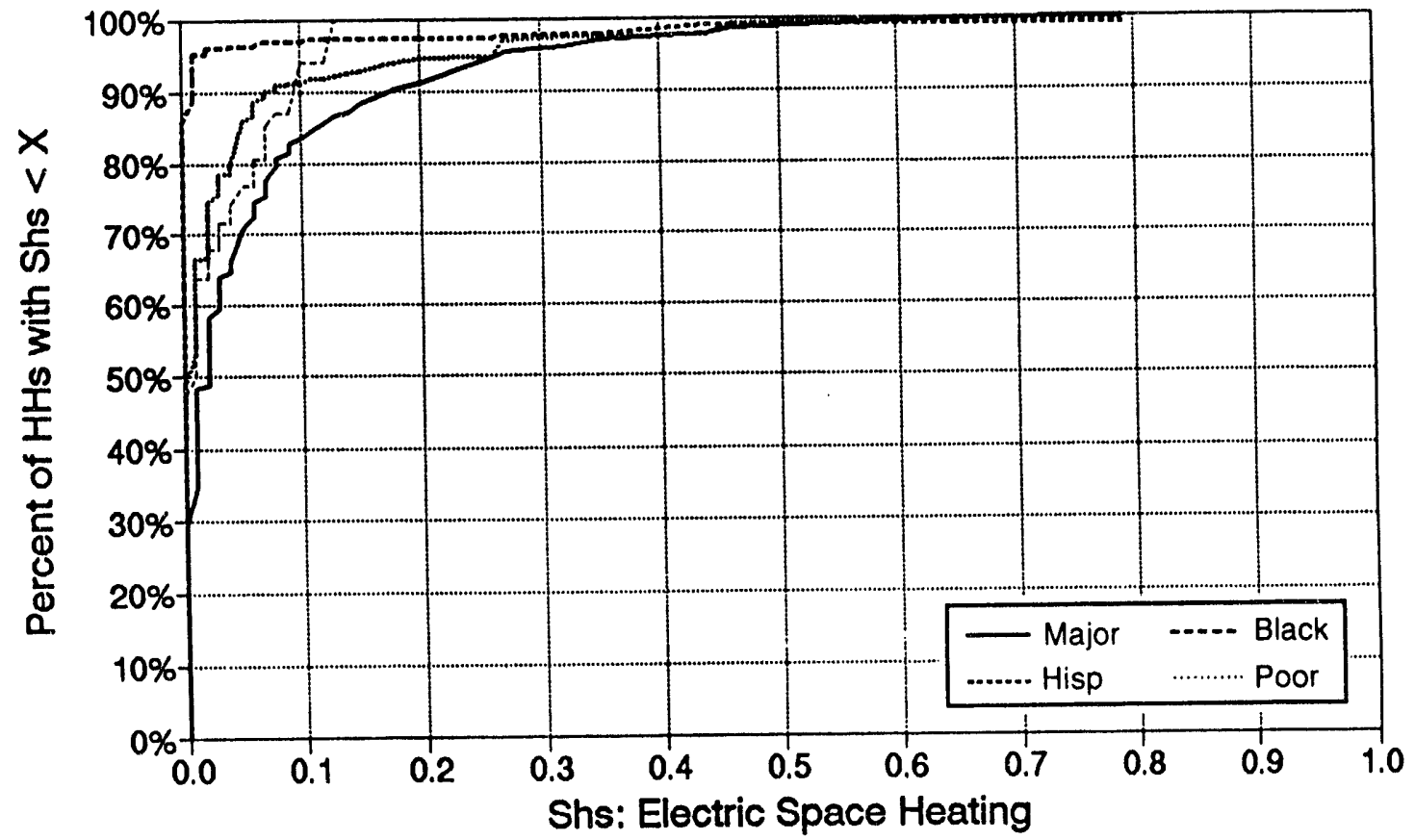

f. Electric Space Heating Share by Ethnicity and Poverty

FIGURE 2 (Cont.) 


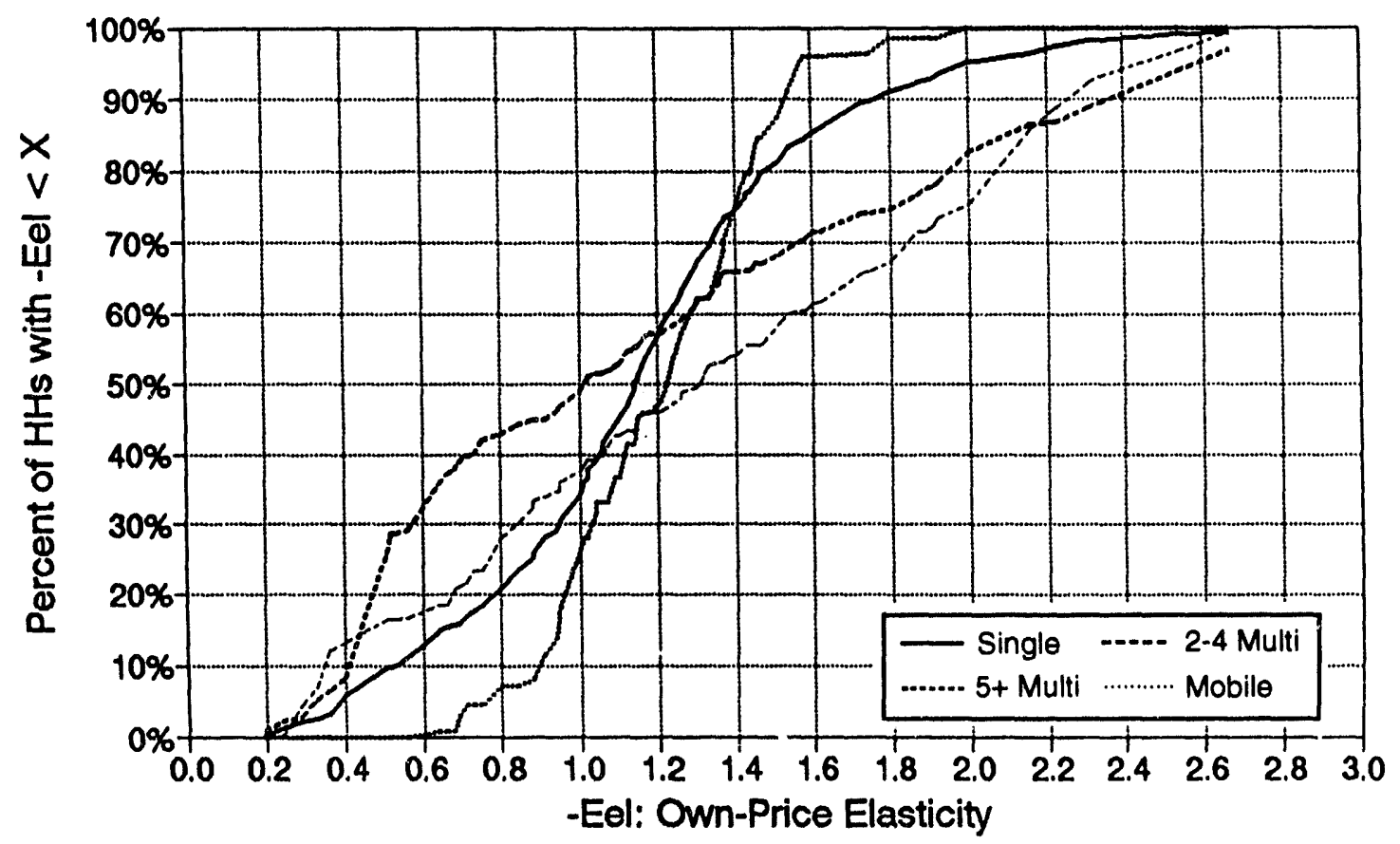

a. Electricity Price Elasticity by House Type

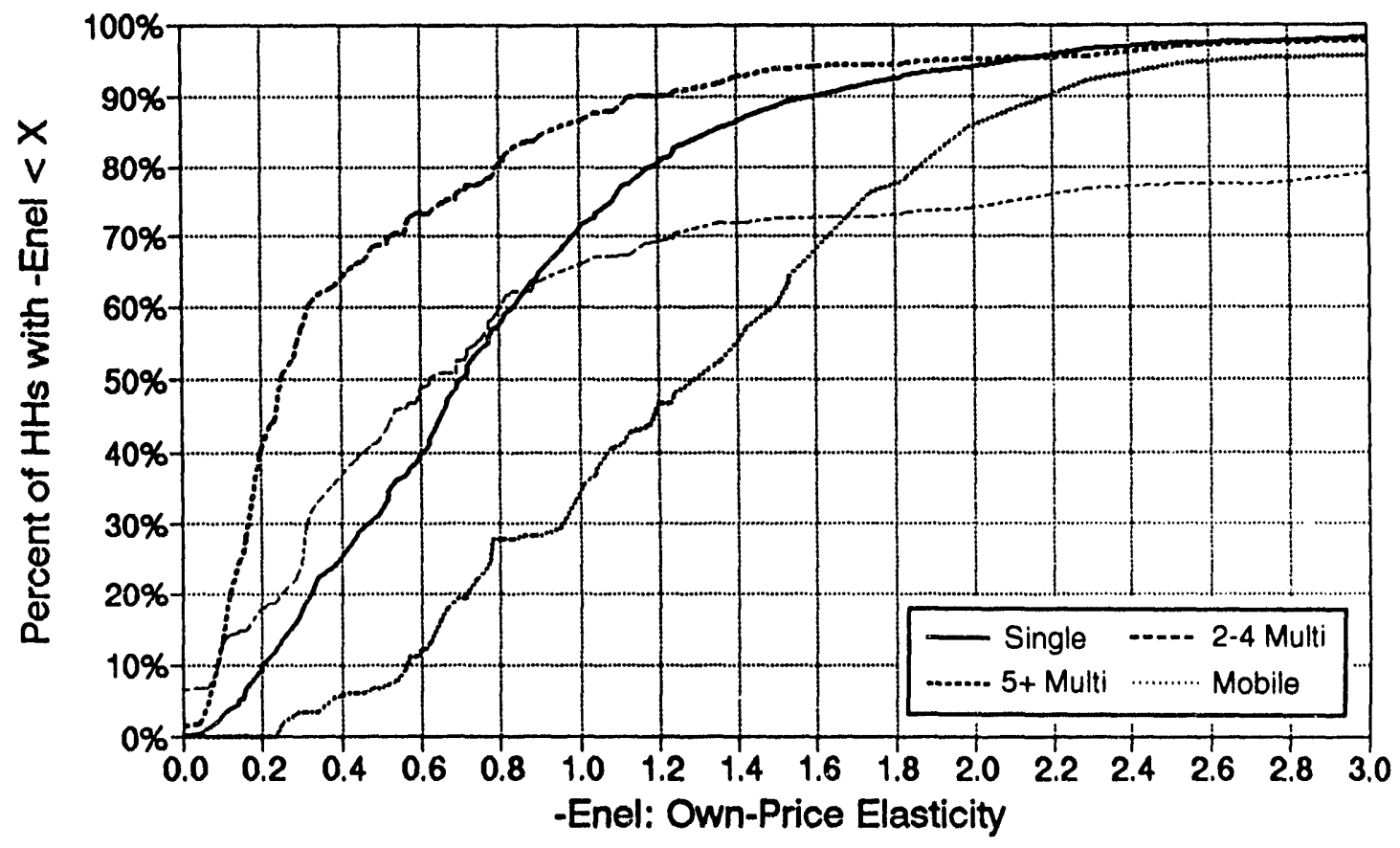

b. Non-Electric Energy Price Elasticity by House Type

FIGURE 3 Price Elasticities and Appliance Shares by House Type 

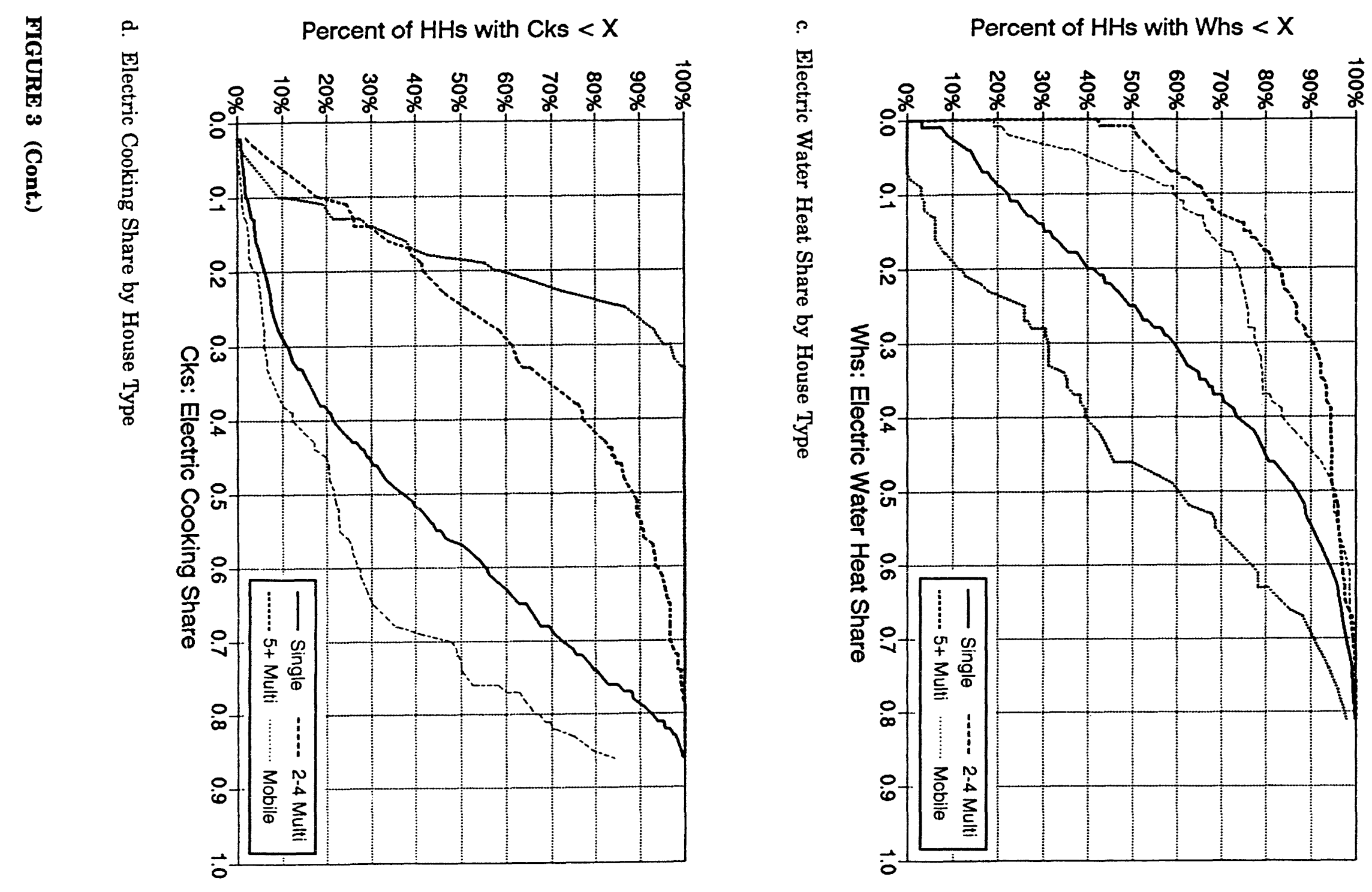


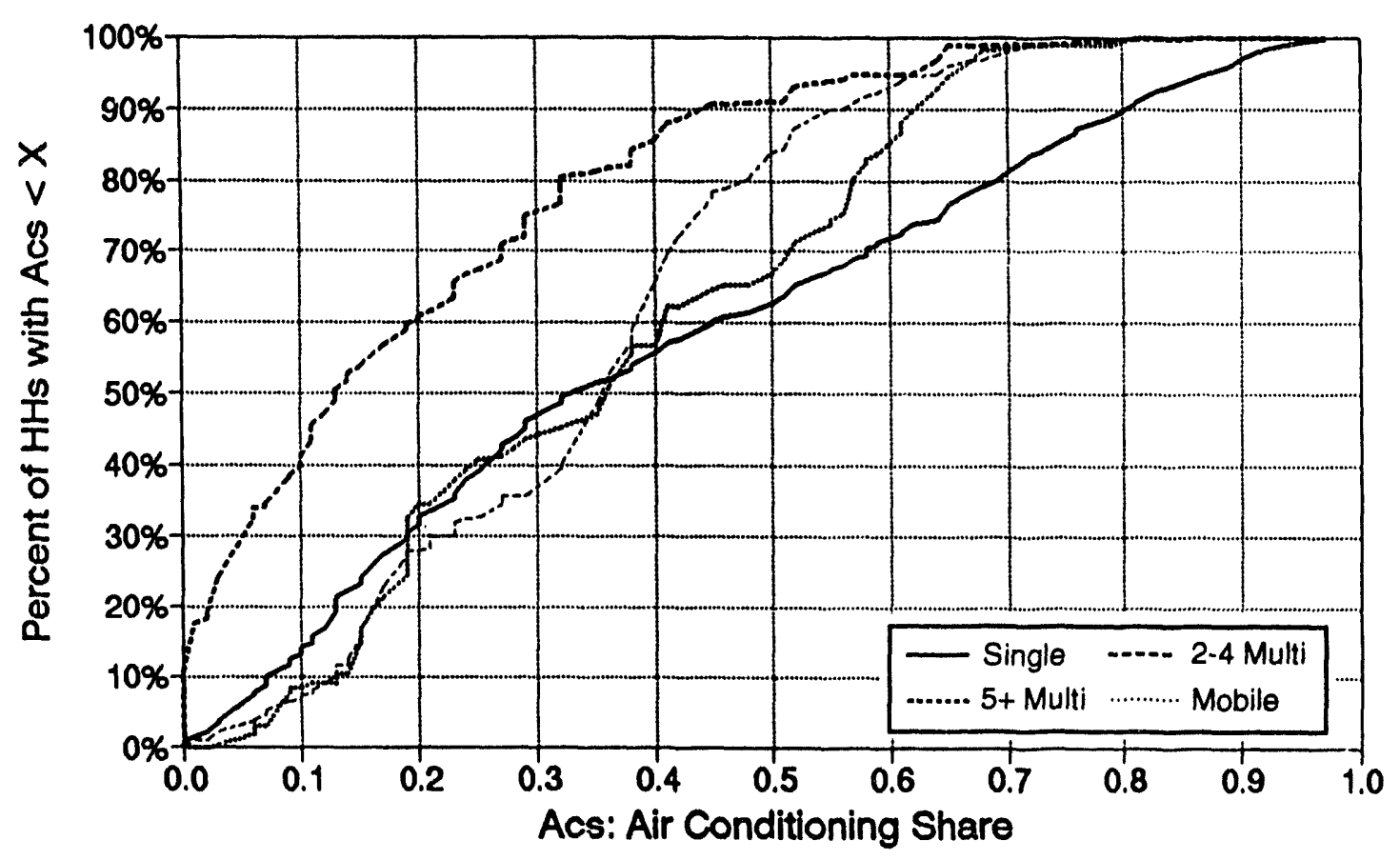

e. Air Conditioning Share by House Type

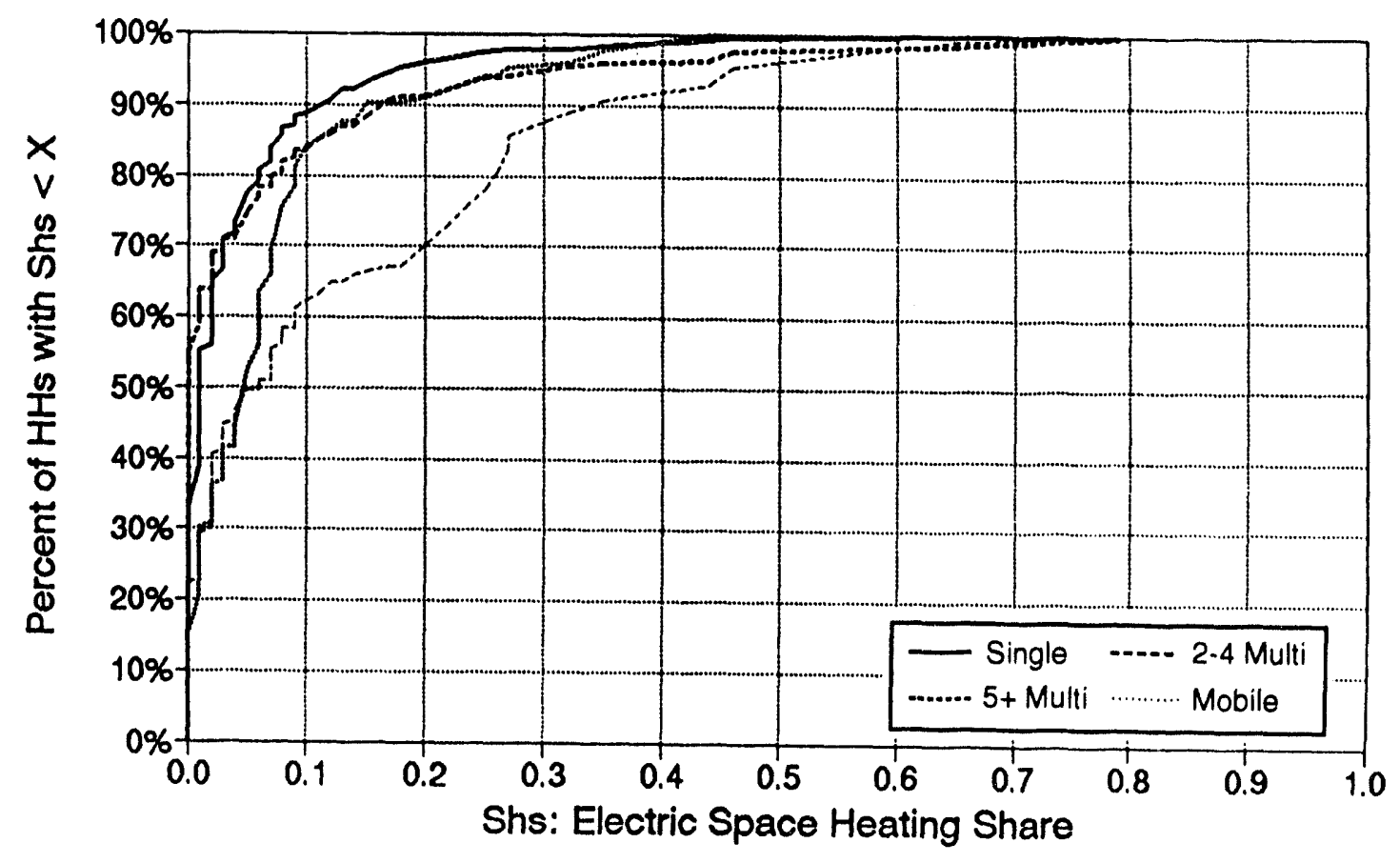

f. Electric Space Heating Share by House Type

FIGURE 3 (Cont.) 


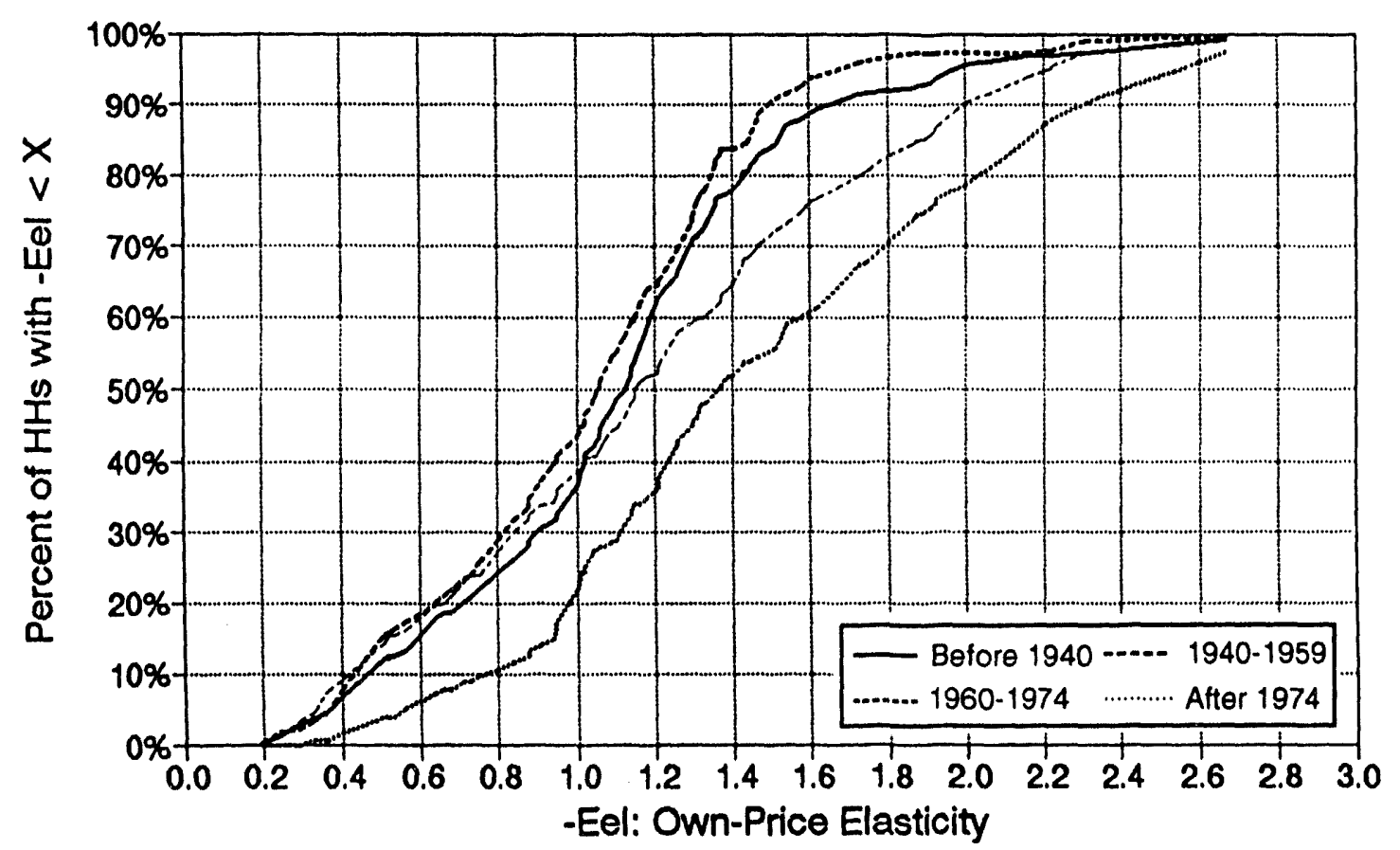

a. Electricity Price Elasticity by House Vintage

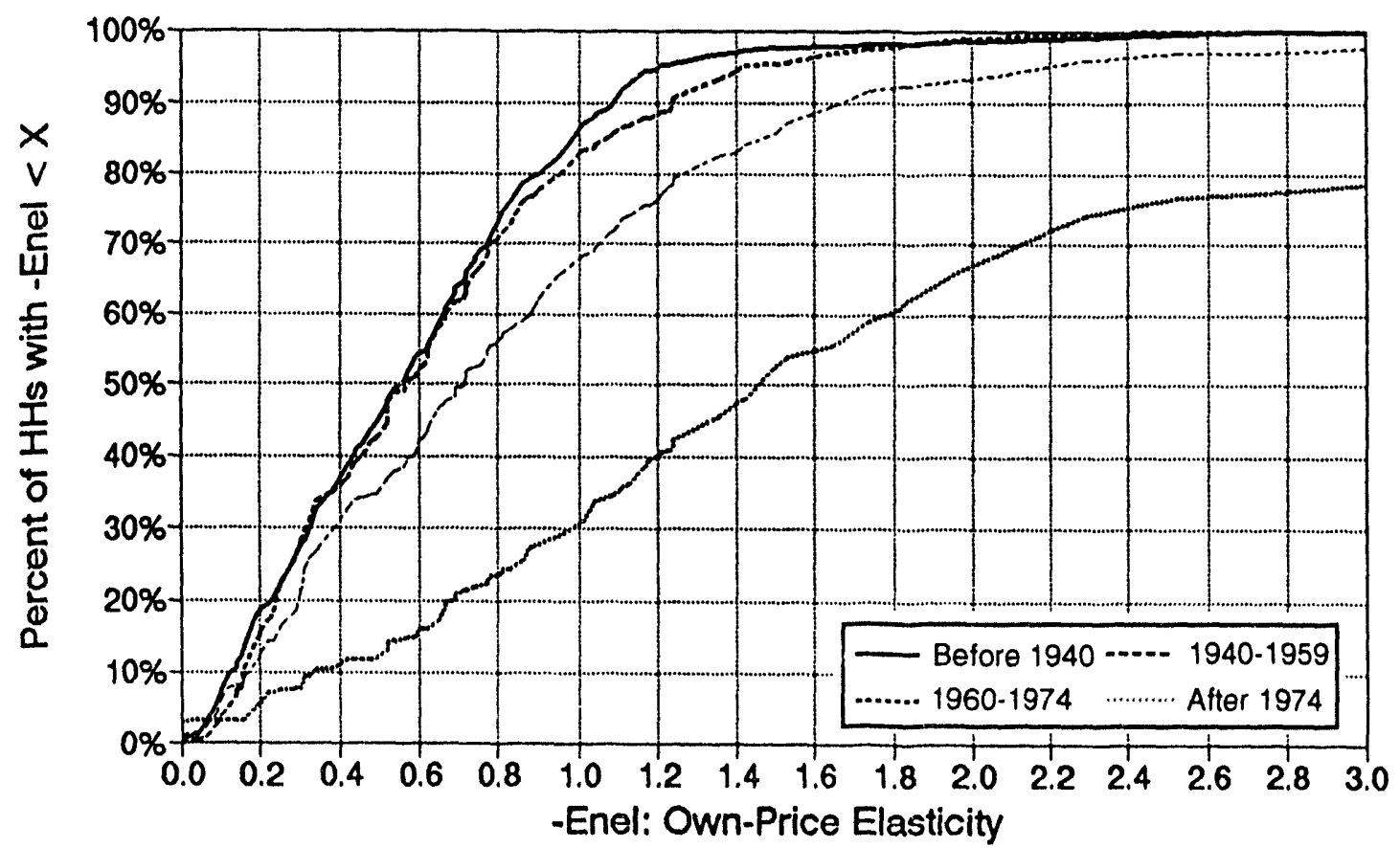

b. Non-Electric Energy Price Elasticity by House Vintage

FIGURE 4 Elasticities and Appliance Shares by House Vintage 


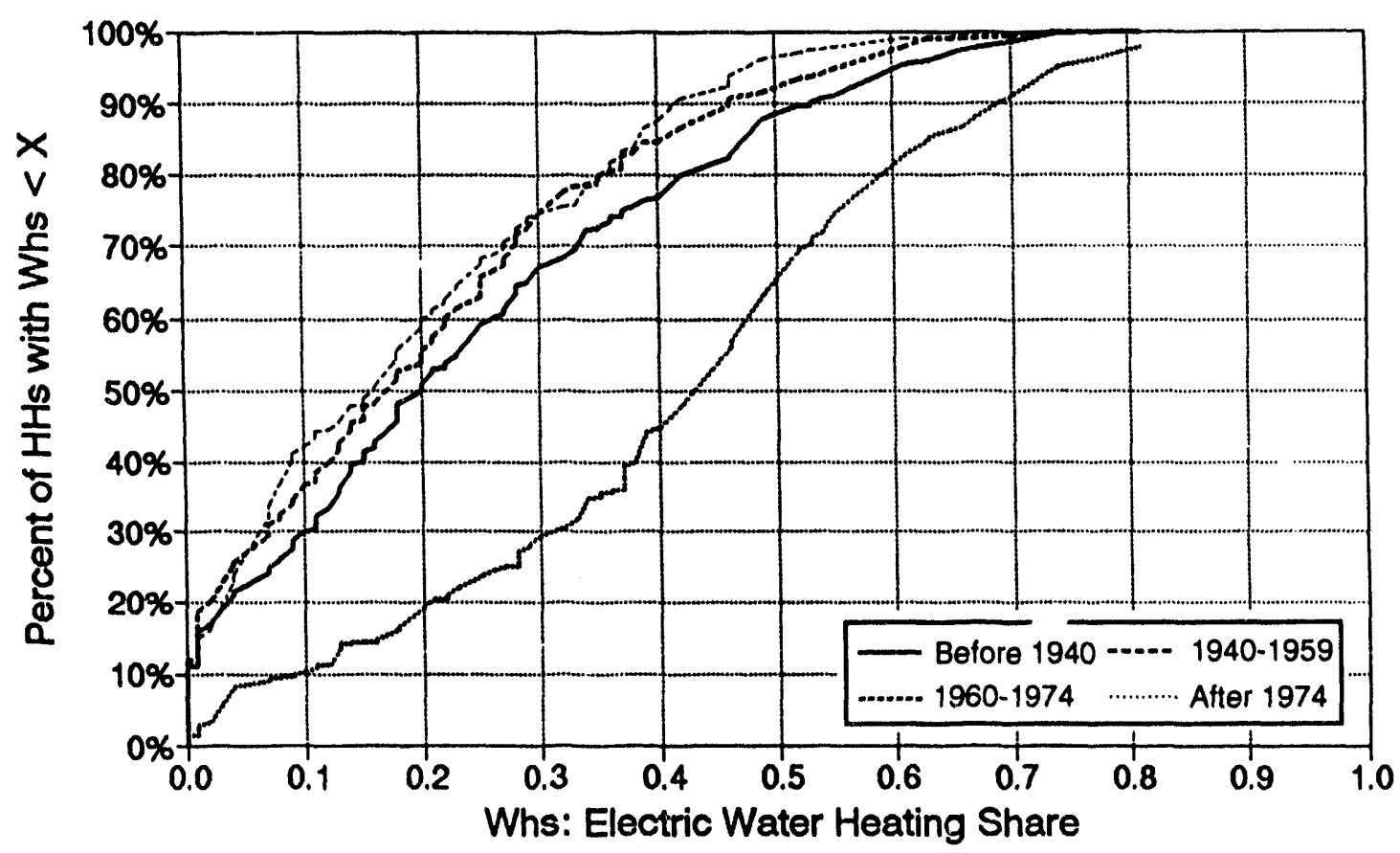

c. Electric Water Heating Share by House Vintage

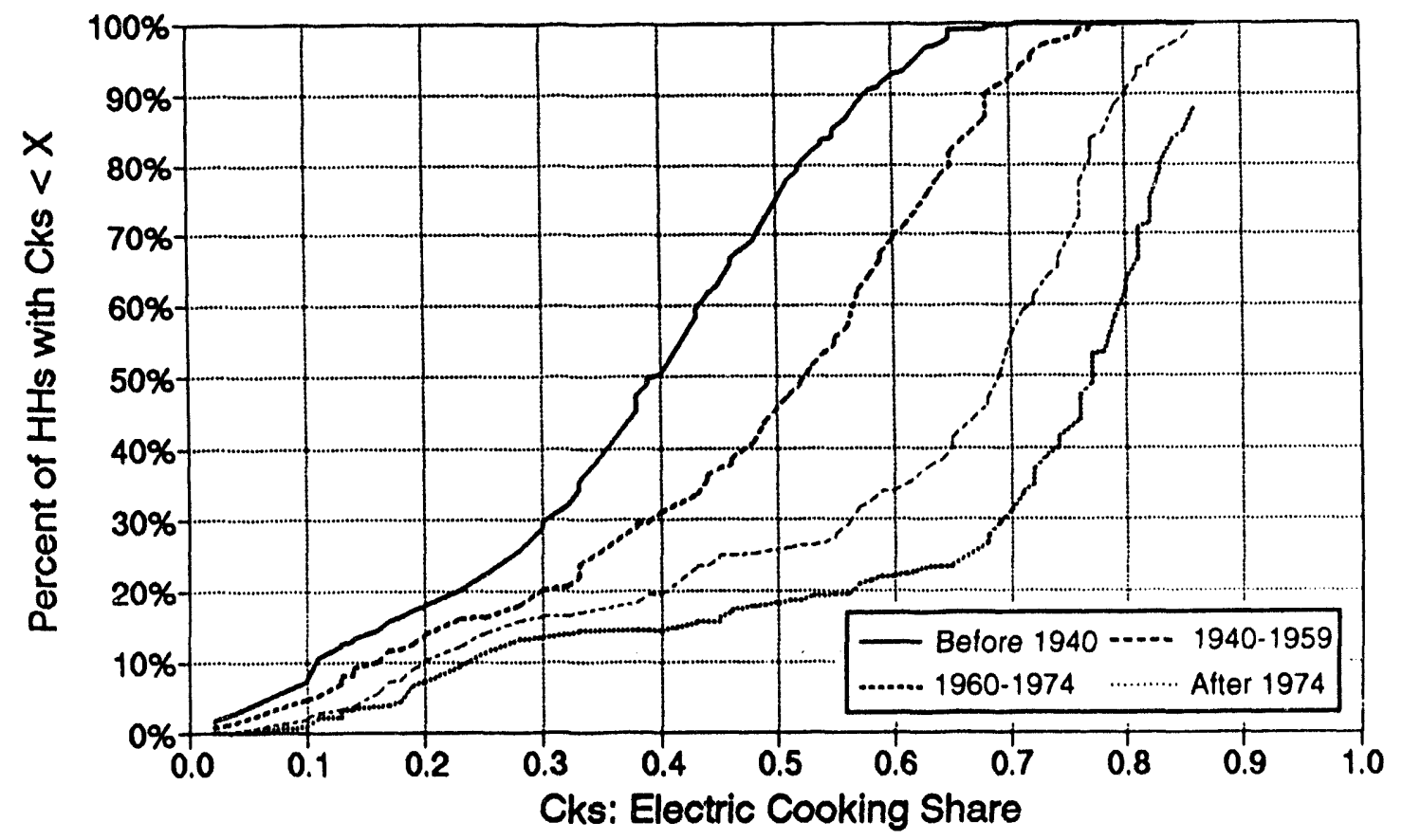

d. Electric Cooking Share by House Vintage

FIGURE 4 (Cont.) 


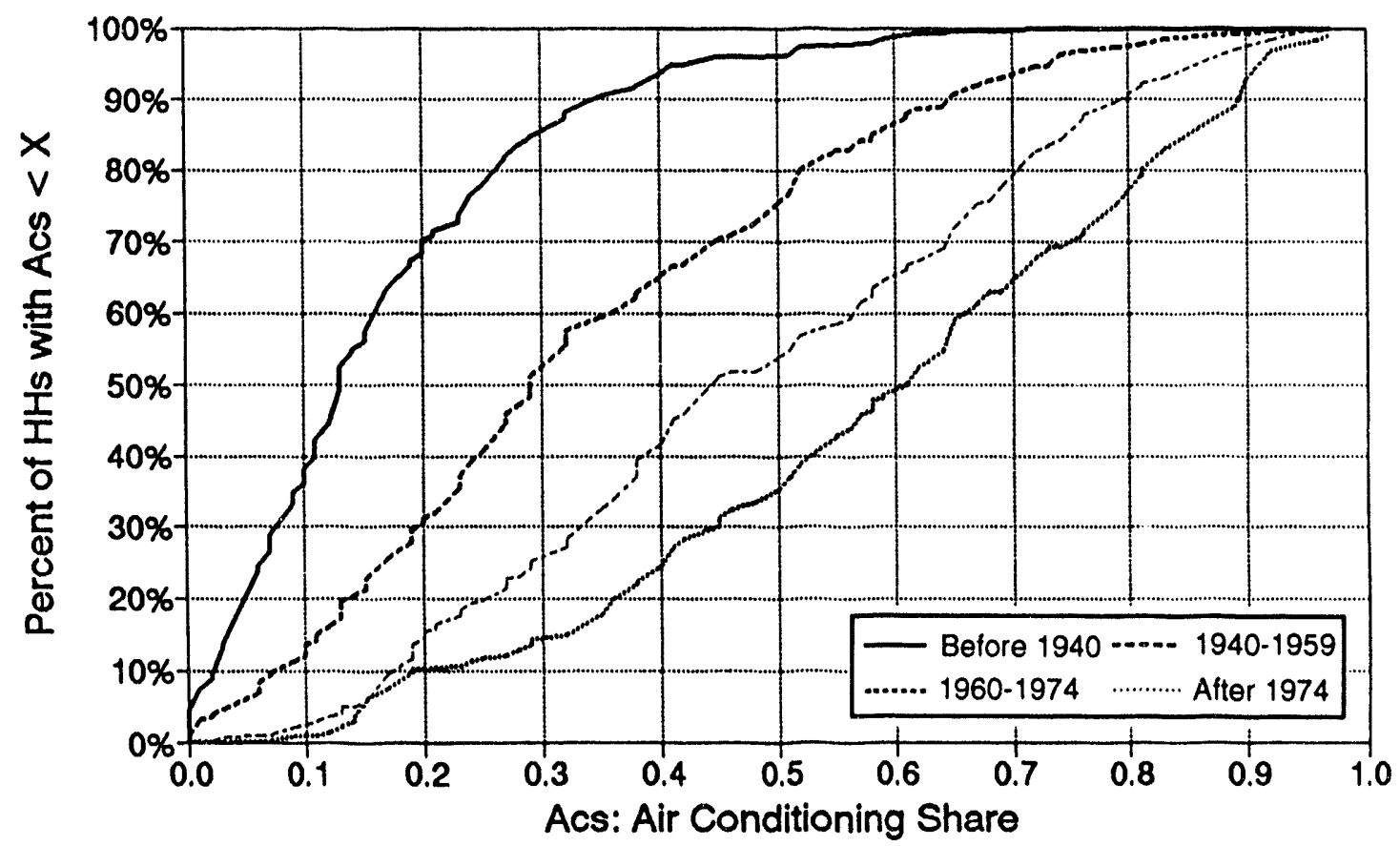

e. Air Conditioning Share by House Vintage

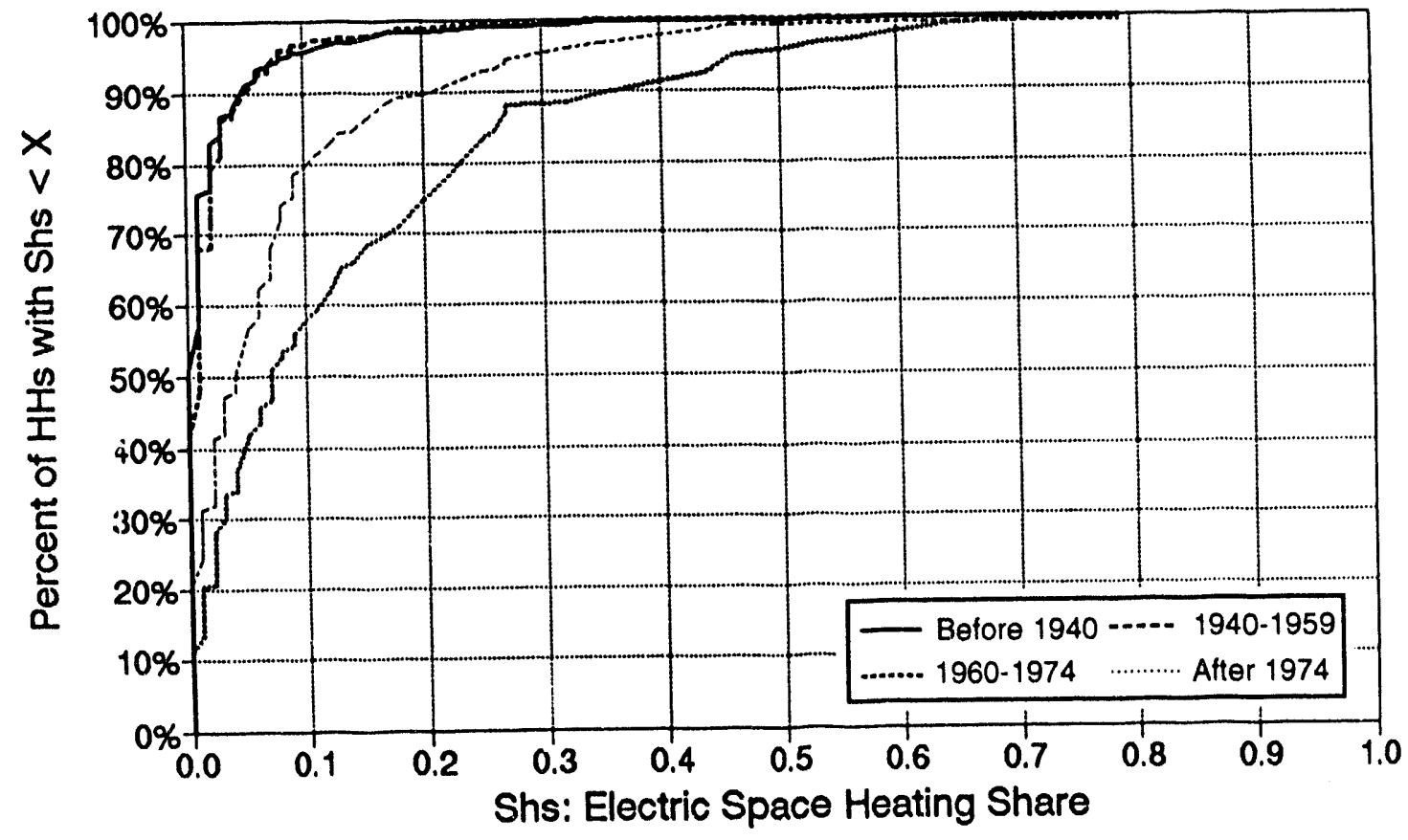

f. Electric Space Heating Share by House Vintage

FIGURE 4 (Cont.) 


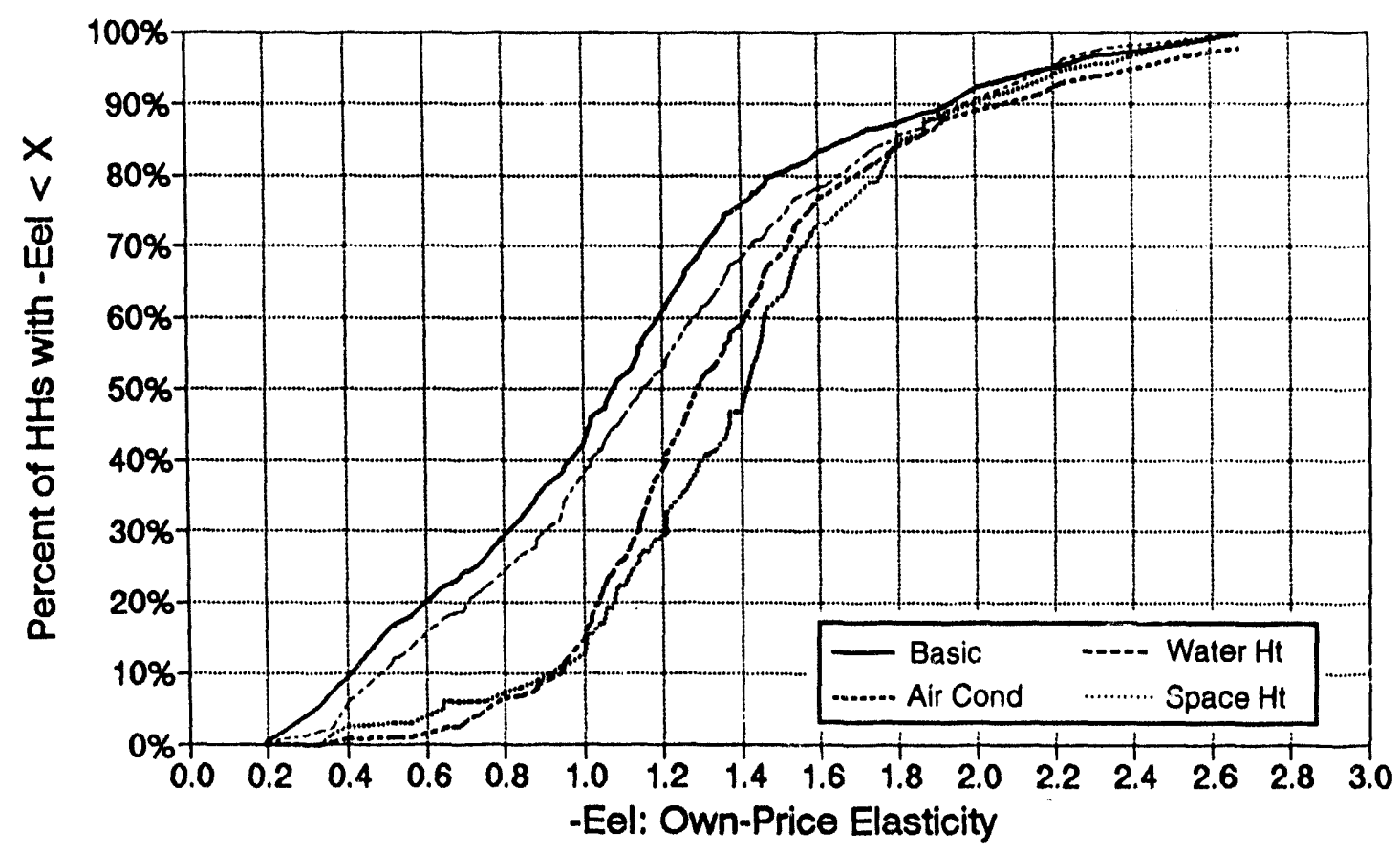

a. Electricity Price Elasticity by Appliance Use

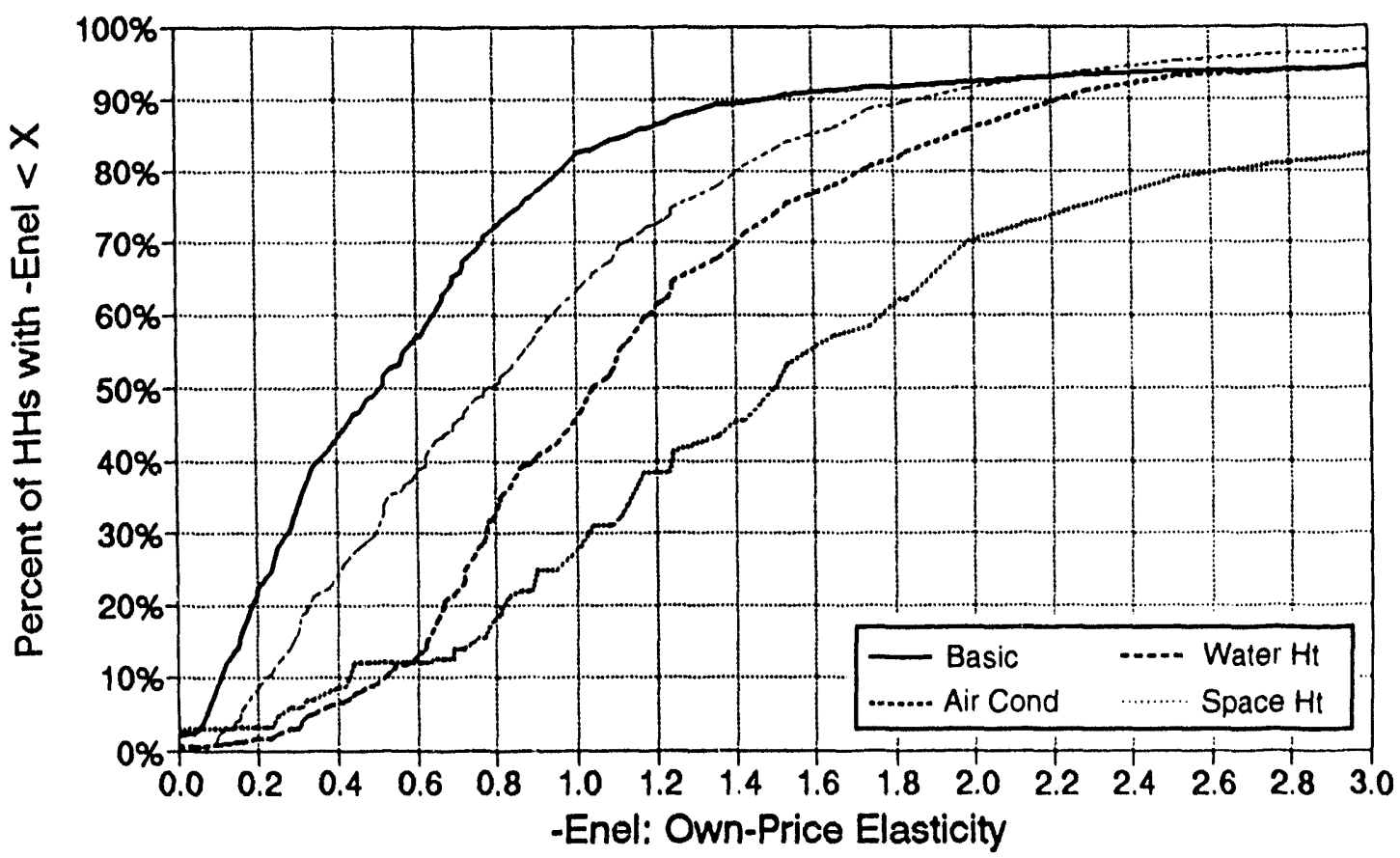

b. Non-Electric Energy Price Elasticity by Appliance Use

FIGURE 5 Price Elasticities and Appliance Shares by Appliance Use 


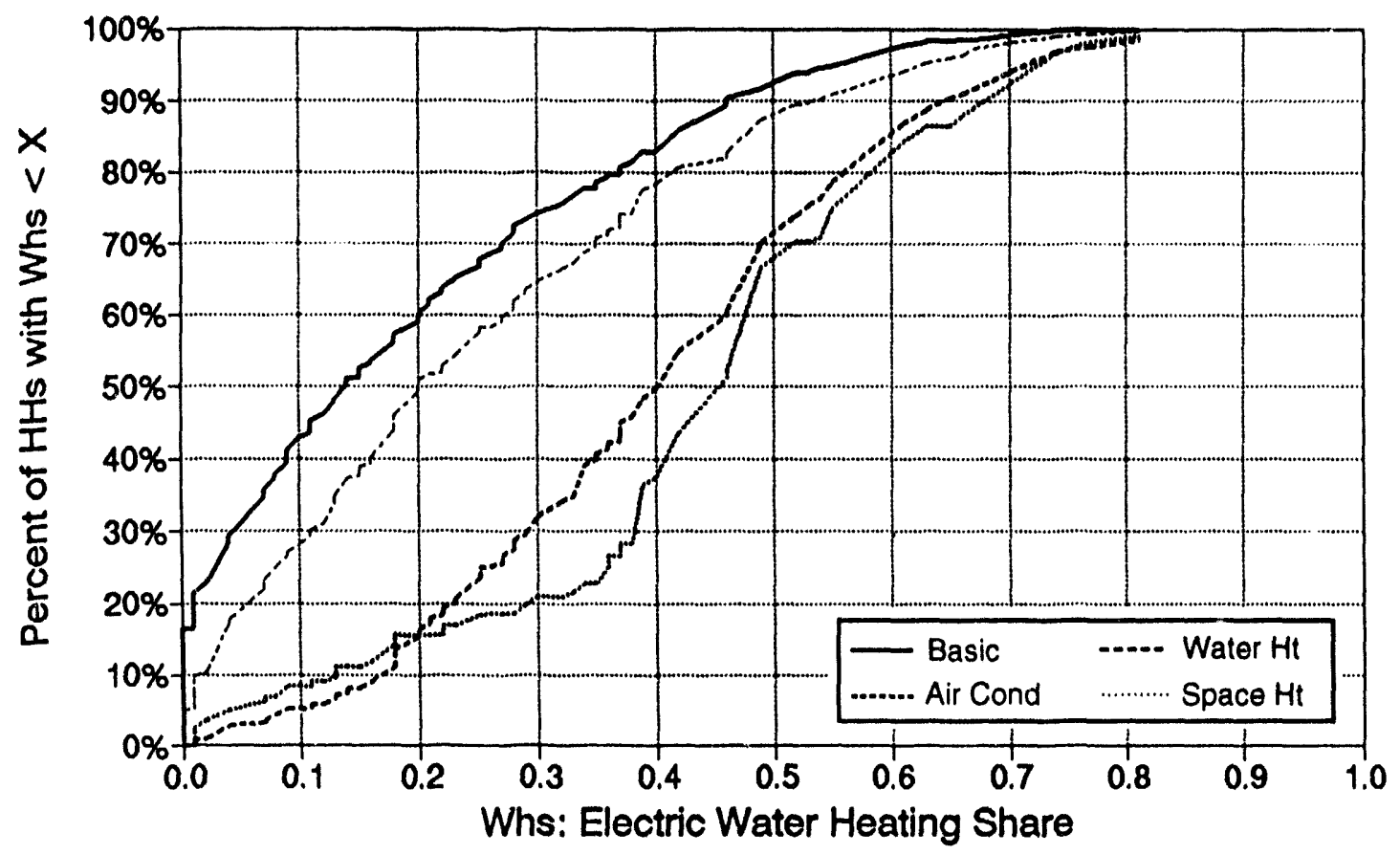

c. Electric Water Heating Share by Appliance Use

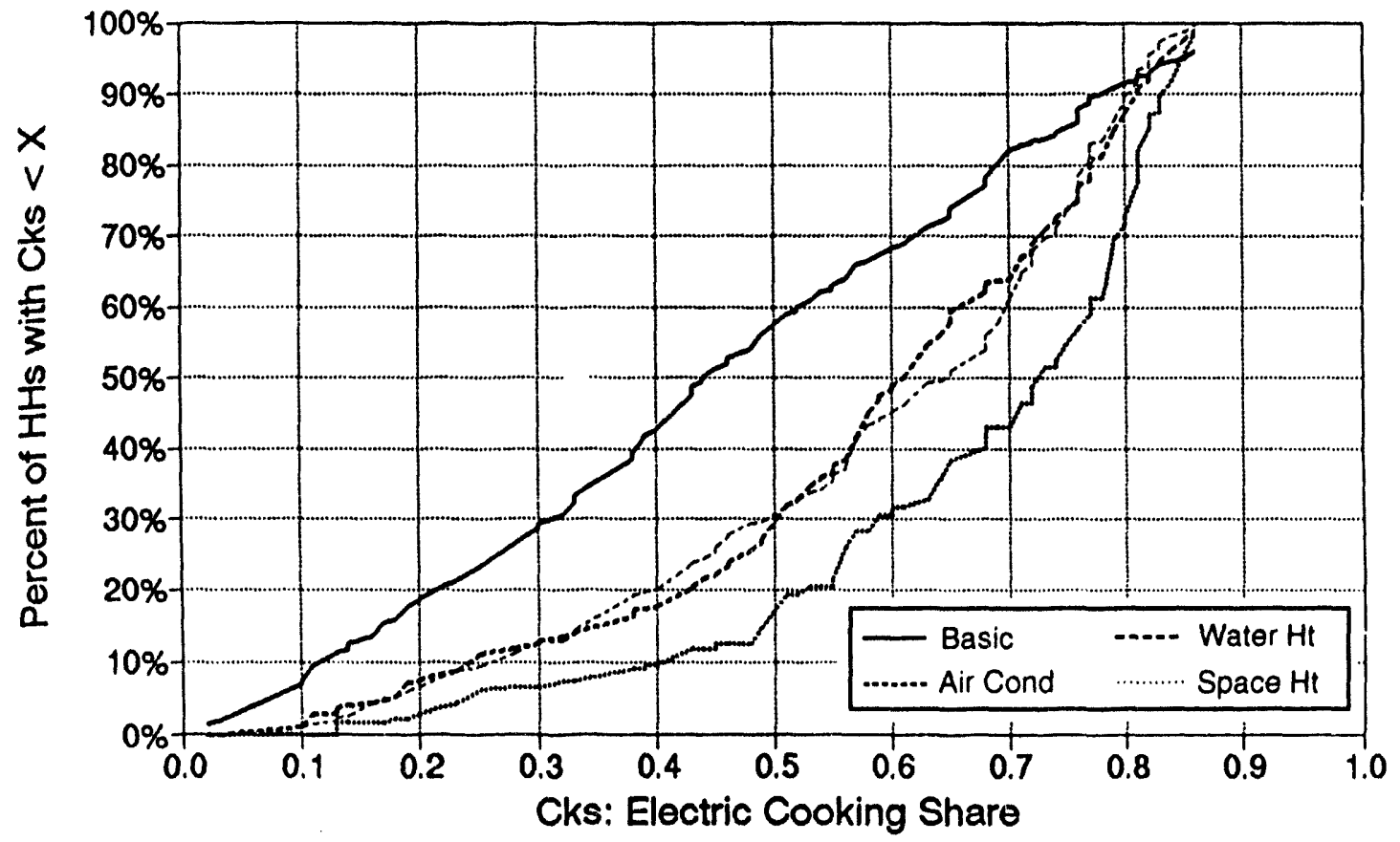

d. Electric Cooking Share by Appliance Use

FIGURE 5 (Cont.) 


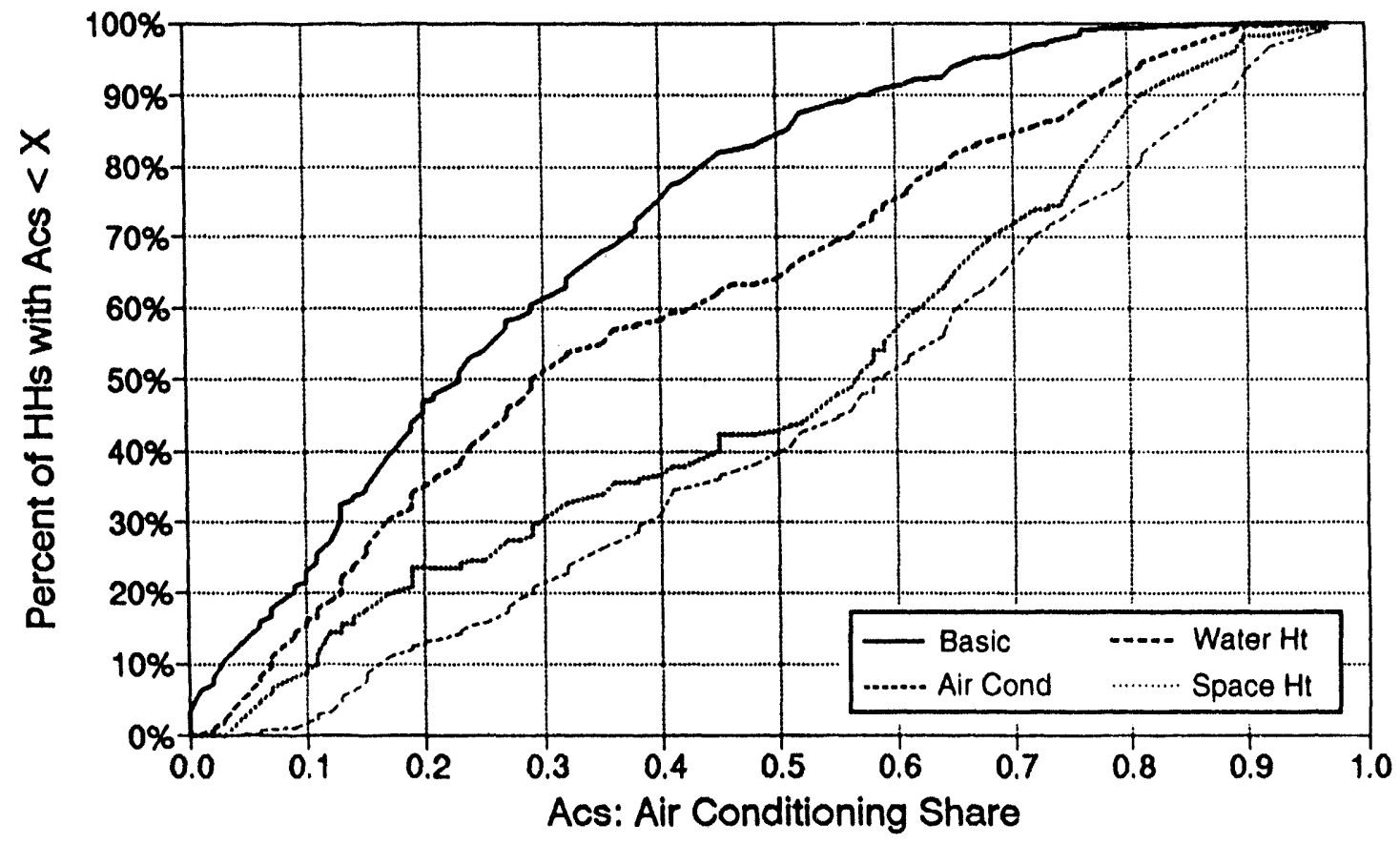

e. Air Conditioning Share by Appliance Use

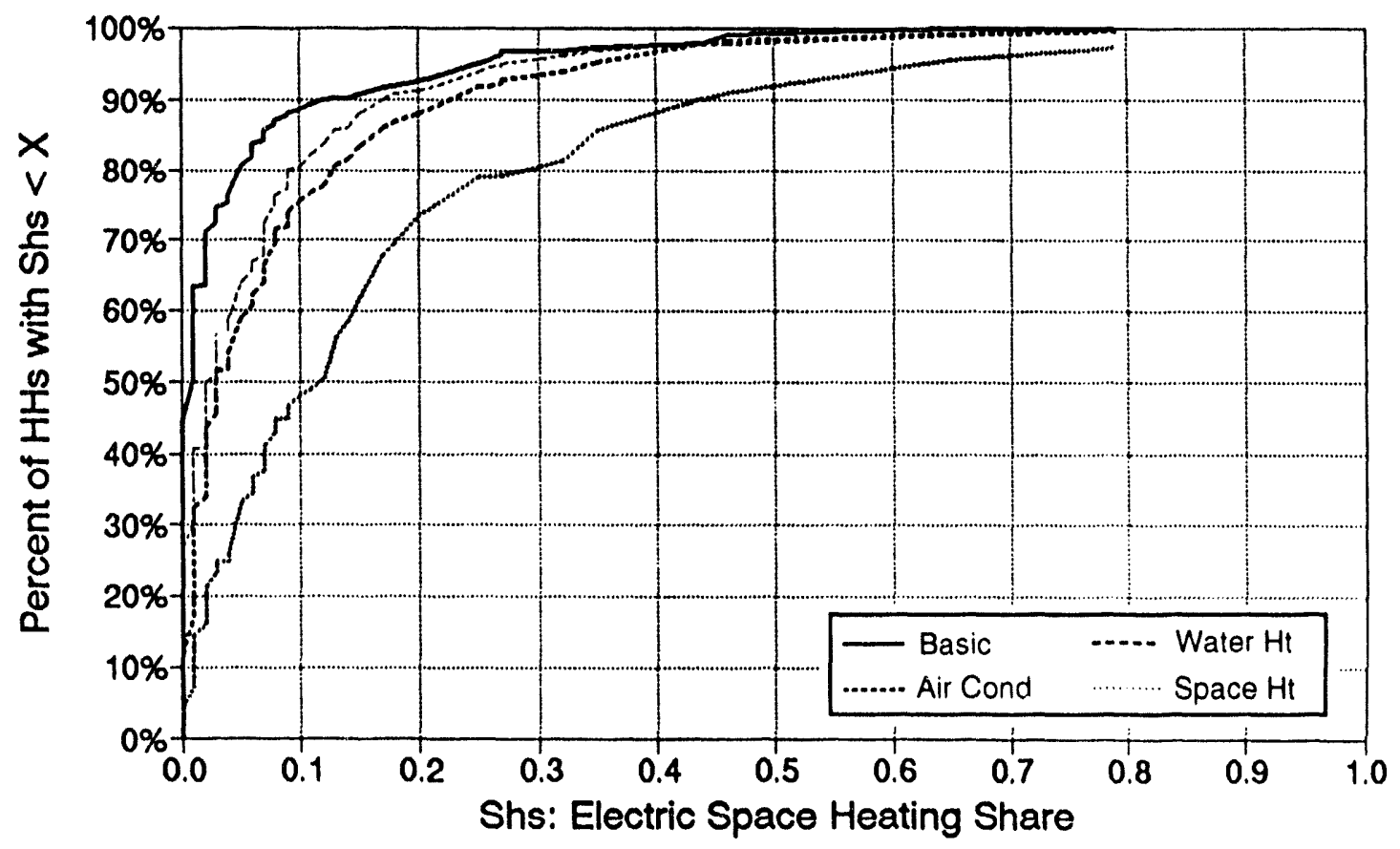

f. Electric Space Heating Share by Appliance Use

FIGURE 5 (Cont.) 


\section{REFERENCES}

Butler, J.G., and D.A. Poyer, 1993, User's Guide for the Energy Policy Socioeconomic Impact Model, Version 1.0, Argonne National Laboratory, Argonne, Ill.

Cowing, T.G., and D.L. McFadden, 1984, Microeconomic Modeling and Policy Analysis: Studies in Residential Energy Demand, Academic Press, New York.

DOE, 1983, Residential Energy Consumption Survey 1981-1982, public-use data tape, U.S. Department of Energy, Energy Information Administration, Washington, D.C.

DOE, 1985, Residential Energy Consumption Survey 1982-1983, public-use data tape, U.S. Department of Energy, Energy Information Administration, Washington, D.C.

DOE, 1987, Residential Energy Consumption Survey 1984-1985, public-use data tape, U.S. Department of Energy, Energy Information Administration, Washington, D.C.

DOE, 1989, Residential Energy Consumption Survey 1987, public-use data tape, U.S. Department of Energy, Energy Information Administration, Washington, D.C.

Fox Software, Inc., 1991, FoxPro 2.0 Commands and Functions, Fox Holdings, Inc., Perrysville, Ohio.

Khazzoom, J.D., 1986, An Econometric Model Integrating Conservation Measures in the Residential Demand for Electricity, JAI Press, Greenwich, Conn.

Maddala, G.S., 1983, Limited-Dependent and Qualitative Variables in Econometrics, Cambridge University Press, Cambridge, U.K.

Mathsoft, Inc., 1993, Mathcad 4.0 User's Guide, Cambridge, Mass.

SAS Institute, Inc., 1988, SAS/ETS User's Guide, Version 6, 1st Ed., Cary, N.C.

U.S. Department of Labor, 1991, Consumer Expenditure Survey, Interview Survey 1989, Bureau of Labor Statistics, Washington, D.C. 
(1) 
APPENDIX A:

EPSIM TECHNICAL SPECIFICATION WITH REPRESENTATIVE VALUES 


\section{APPENDIX A: \\ EPSIM TECHNICAL SPECIFICATION WITH REPRESENTATIVE VALUES}

This appendix contains a complete specification of the EPSIM econometric submodels, except for the values of the parameter vectors. It was prepared with Mathcad 4.0 mathematical software (Mathsoft 1993). When run with the Mathcad host program, the calculations presented in Appendix $A$ are a working model of the mathematical equations and expressions contained in EPSIM. The ":=" symbol denotes variable and function definitions, while the "=" symbol displays the current value of the specified variable or expression. Before any variable can be evaluated (or used in an expression to be evaluated), it must have appeared on the left side of a previous Mathcad definition. A Mathcad document operates in a manner similar to a spreadsheet template, performing its calculations in sequence from top to bottom and from left to right. In EPSIM Version 1.0, the calculations described in this appendix are performed on each of the 1,606 households that make up the Midwest sample of the 1987 Residential Energy Consumption Survey (DOE 1989). 


\section{Exogenous Variables:}

House Vintage: unt $:=75$

House Type: htyp $:=1$

Race: black : $=0$

Metro Location: incity : 0

Heated Area: area $:=2430$

Latin:

hisp $:=0$

Heat degreo-days: hdd65 :=4555

Household Size: hhsize $:=2$

Household Income: thinc $:=62500$

Cool degreo-days: cdd65:=1451

Poverty:

poor : $:=0$

Gender:

fembd : $=0$

Electricity price: $\quad \mathrm{Pel}:=23.66$

Age of head: agehd : $=45$

Electricity and Non-energy Prices: Pc $:=1.505$ Pelc $:=18.66$ Melc $:=86.50$

Logit function definition: logit(pi) $:=\frac{e^{p i}}{1+e^{p i}}$ Vector of Explanatory Variables: $X s(P c):=$ Non-Electric Energy Price:

ne := READPRN(ne) pn:=READPRN(pn) pn20:=-2.414

$\alpha:=\operatorname{logit}\left(\mathrm{ne}^{\mathrm{T}} \cdot \mathrm{Xs}(\mathrm{Pc})\right) \quad \mathrm{mr}:=\frac{(1-\alpha) \cdot \ln (1-\alpha)}{\alpha}+\ln (\alpha)$

Pnel : $=\mathrm{pn}^{\mathrm{T}} \cdot \mathrm{Xs}(\mathrm{Pc})+\mathrm{pn} 20 \cdot \mathrm{mr} \quad \mathrm{Pnel}=5.38$

Household Expenditures:

cpiu $:=1.505 \quad$ cpiu89 $:=$ cpiu $1.0851 \quad \beta:=\operatorname{logit}(-1.823-.561 \cdot$ bleck $-.282 \cdot$ hisp $)$

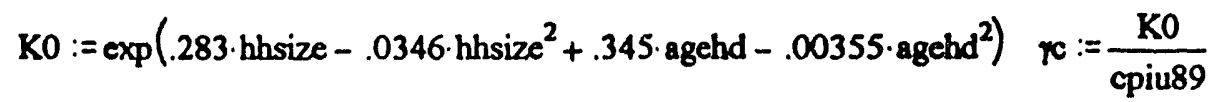

$Y d:=0.961 \cdot$ hhinc $-1.087 \cdot 10^{-6} \cdot$ hhinc $^{2} \quad M:=((1-\beta) \cdot \gamma \cdot$ cpiu $+\beta \cdot Y d) \cdot 4$

$M=51358 \quad \gamma=3918$

Discretionary Expenditure Parameters: $\quad \beta \mathrm{e}:=.007 \quad \beta \mathrm{el}:=.003$

\section{Electrical Appliance Use Probabilities:}

Water Heating: wh := if(black, READPRN(whshr2), READPRN(whshr1))

$$
\text { whs }(\text { Pel, Pnel }):=\operatorname{logit}\left(w^{\mathrm{T}} \cdot \mathrm{Xs}\left(\frac{\mathrm{Pel}}{\mathrm{Pnel}}\right)\right) \quad \text { whs }(\text { Pel, Pnel })=0.196
$$

Space Heating: sh := if(black, READPRN(shshr2), READPRN( shshr1))

$$
\operatorname{shs}(\text { Pel, Pnel }):=\operatorname{logit}\left(\operatorname{sh}^{\top} \cdot \mathrm{Xs}\left(\frac{\text { Pel }}{\text { Pnel }}\right)\right) \quad \text { shs }(\text { Pel, Pnel })=0.031
$$

Cooking: $\quad$ ck : $=$ if(black, READPRN(ckshr2), READPRN(ckshr1))

$$
\operatorname{cks}(\text { Pel, Pnel }):=\operatorname{logit}\left(\mathrm{ck}^{\mathrm{T}} \cdot \mathrm{Xs}\left(\frac{\mathrm{Pel}}{\mathrm{Pnel}}\right)\right) \quad \operatorname{cks}(\text { Pel, Pnel })=0.730
$$

Central AC: $\quad$ ac : : if(black, READPRN(acshr2), READPRN(acshr1))

$$
\operatorname{acs}(\text { Pel, Pnel }):=\operatorname{logil}\left(\operatorname{ac}^{\mathrm{T}} \cdot \mathrm{Xs}\left(\frac{\mathrm{Pel}}{\mathrm{Pc}}\right)\right) \quad \operatorname{acs}(\text { Pel, Pnel })=0.839
$$


Non-discretionary Energy Consumption:

$$
\begin{aligned}
& \text { gl := if(black, READPRN(glparm2), READPRN(glparm1)) } \\
& \text { ge := if(black, READPRN(geparm2), READPRN(geparm1)) }
\end{aligned}
$$

Vector of Explanatory Variables: Xe(Pel,Pnel $):=$

$\operatorname{rel}($ Pel, Pnel $):=\mathrm{gl}^{\mathrm{T}} \cdot \mathrm{Xe}($ Pel, Pnel $)$ $\operatorname{rel}($ Pel, Pnel $)=28.66$

$\gamma($ Pel, Pnel $):=g e^{\mathrm{T}} \cdot$ Xe(Pel, Pnel $)+\operatorname{rel}($ Pel, Pnel $)$ $r e($ Pel, Pnel $)=102.62$

$\operatorname{pel}:=\gamma(\mathrm{Pel}, \mathrm{Pnel})-\operatorname{rel}(\mathrm{Pel}, \mathrm{Pnel})$ $\mathrm{mel}=73.97$

Guesses: Qe $:=100 \quad$ Qel $:=50 \quad \mathrm{Pe}:=10$

Given

Energy Demand:

$\mathrm{Q} e=\gamma e($ Pel, Pnel $)+\frac{\beta e}{\mathrm{Pe}} \cdot(M-\mathrm{Pc} \cdot x \mathrm{c})$

Electricity Demand:

Qel $=$ yel $($ Pel, Pnel $)+\frac{\text { Bel }}{\text { Pelc }} \cdot(M-P c \cdot y c)$

Average Energy Price:

$P e=\frac{\text { Melc }+P e l c \cdot Q_{e l}+P_{n e l} \cdot\left(Q_{e}-Q_{e l}\right)}{Q e}$

Solve for Qe, Qel, and Pe: $Q($ Pel, Pnel $):=$ find $(Q e, Q e l, P e) \quad Q(P e l, P n e l)=\left(\begin{array}{l}136.038 \\ 35.964 \\ 9.523\end{array}\right)$

Energy Consumption:

Qel : $=Q(\text { Pel, Pnel })_{1}$ Qnel : $=Q(\text { Pel,Pnel })_{0}-Q(\text { Pel, Pnel })_{1}$

$\mathrm{Qel}=35.96$

Qnel $=100.07$

Electricity Expenditures: $\quad$ Melc + Pelc $\cdot$ Qel $=758$

Non-Electric Energy Expns: $\quad$ Pnel. Qnel $=538$ 
Calculation of Electricity Own-Price Elasticity:

Change in GamL with respect to Pel:

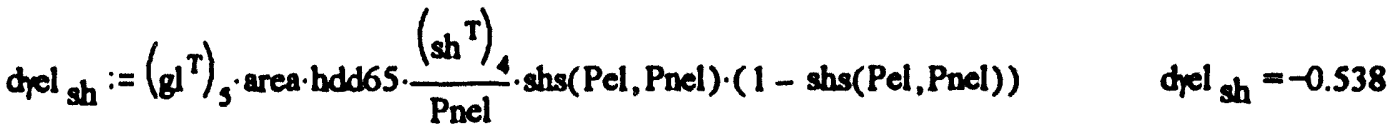

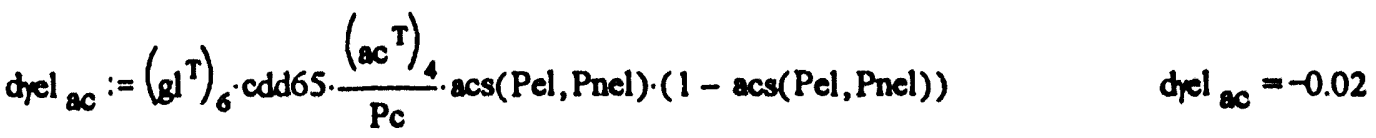

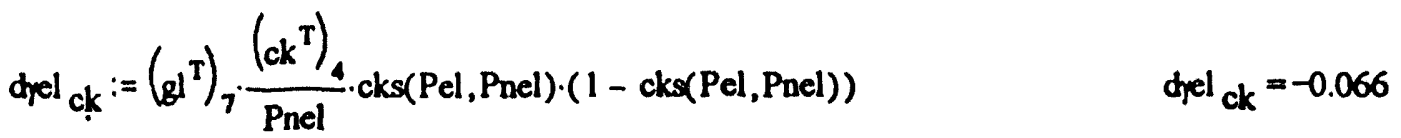

$$
\begin{aligned}
& \text { deel }_{\text {wh }}:=\left({ }_{g l} \mathrm{~T}\right)_{8} \cdot \frac{\left(w^{\top} \mathrm{T}\right)}{\text { Pnel }_{4}} \cdot \text { whs }(\text { Pel, Pnel }) \cdot(1-\text { whs }(\text { Pel, Pnel })) \quad \quad \text { del }_{\text {wh }}=-0.988 \\
& \text { dyel : = dyel }{ }_{\text {sh }}+\text { drel }_{\mathrm{ac}}+\text { drel }_{\mathrm{ck}}+\text { dyel }_{\mathrm{wh}} \quad \text { del }=-1.612
\end{aligned}
$$

Change in Qel with respect to Pel:

dQel : = dyel

$$
\begin{array}{ll}
\mathrm{dQel}=-2.004 & \mathrm{Qel}=\mathbf{=} 5.964 \\
\mathrm{dPel}:=1 & \mathrm{Pel}=\mathbf{2 3 . 6 6}
\end{array}
$$

Electricity Own-Price Elasticity:

$\varepsilon_{\mathrm{el}}:=\frac{\mathrm{drel}}{\mathrm{dPel}} \frac{\mathrm{Pel}}{\mathrm{Qel}_{\mathrm{el}}} \quad \varepsilon_{\mathrm{el}}=-1.06$

Numerically Calculated Elasticity:

$$
\begin{aligned}
& \mathrm{dQel}:=\mathrm{Q}(\mathrm{Pel}, \mathrm{Pnel})_{1}-\mathrm{Q}(.999 \cdot \mathrm{Pel}, \mathrm{Pnel})_{1} \quad \mathrm{dPel}:=.001 \cdot \mathrm{Pel} \\
& \frac{\mathrm{dQel}}{\mathrm{dPel}} \cdot \frac{\mathrm{Pel}}{\mathrm{Qel}_{\mathrm{el}}}=-1.06
\end{aligned}
$$


Calculation of Non-Electric Energy Own-Price Elasticity:

Change in GamNel with respect to Pnel:

dmel sh $_{\text {sh }}:=-\left(\mathrm{ge}^{\mathrm{T}}\right)_{3} \cdot \operatorname{area} \cdot$ hdd65 $\left(\mathrm{sh}^{\mathrm{T}}\right)_{4} \cdot \frac{\mathrm{Pel}}{\mathrm{Pnel}^{2}} \cdot \operatorname{shs}(\mathrm{Pel}, \mathrm{Pnel}) \cdot(1-\operatorname{shs}(\mathrm{Pel}, \mathrm{Panel})) \quad$ dpael $_{\text {sh }}=-2.075$

dmel $_{\text {ac }}:=0$

dpoel $x=0$

dpnel $\left._{\text {ck }}:=-\left(\mathrm{ge}^{\mathrm{T}}\right)_{7} \cdot(\mathrm{ck})^{\mathrm{T}}\right) \cdot \frac{\mathrm{Pel}}{\mathrm{Pnel}^{2}} \cdot \operatorname{cks}(\mathrm{Pel}, \mathrm{Pnel}) \cdot(1-\mathrm{cks}(\mathrm{Pel}, \mathrm{Pnel})) \quad \quad$ dpucl $\mathrm{ck}=0.074$

dmel wh $:=-\left(g^{T}\right)_{8} \cdot\left(w^{T}\right)_{4} \cdot \frac{\text { Pel }}{\text { Pnel }^{2}} \cdot w h s(P e l, P n e l) \cdot(1-$ whs $(P e l, P n e l)) \quad$ dmel $w_{h}=-10.217$

dmel := dmel $\mathrm{sh}+$ dmel $_{\mathrm{gc}}+$ dmel $_{\mathrm{ck}}+$ dmel $_{\mathrm{wh}} \quad$ dmel $=-12.219$

Change in Qnel with respect to Pnel:

$\begin{array}{lll}d Q \text { nel }:=d m e l-\frac{\beta e-\beta e l}{P_{n e l}{ }^{2}} \cdot(M-P c \cdot r) & \text { dQnel }=-18.512 & \text { Qnel }=100.074 \\ & \text { dPnel }:=1 & \text { Pnel }=5.375\end{array}$

Non-Electric Energy Own-Price Elasticity:

$\varepsilon_{\text {nel }}:=\frac{d \text { Qnel }}{d \text { Pnel }} \cdot \frac{\text { nel }}{\text { Qnel }} \varepsilon_{\text {nel }}=-0.99$

Numerically Calculated Elasticity:

dQnel : $=\left(Q(\text { Pel, Pnel })_{0}-Q(\text { Pel, Pnel })_{1}\right)-\left(Q(\text { Pel, .999.Pnel })_{0}-Q(\text { Pel, .999.Pnel })\right)_{1}$ dPnel :=.001.Pnel $\frac{d Q n e l}{d P n e l} \cdot \frac{\text { Pnel }}{\text { Qnel }}=-0.99$ 


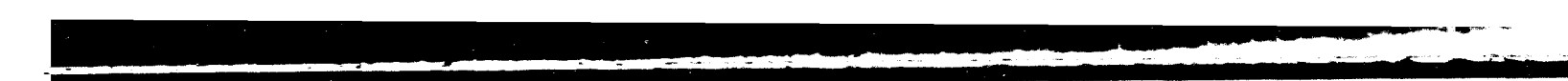

$-\cdots$ 
APPENDIX B:

EPSIM VERSION 1.0 SOURCE CODE AND PARAMETER VALUES 


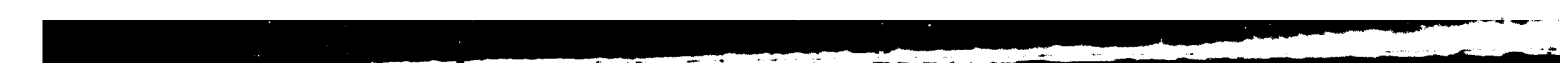




\section{APPENDIX B: \\ EPSIM VERSION 1.0 SOURCE CODE AND PARAMETER VALUES}

Values for the 270 parameters used in EPSIM Version 1.0 were estimated by using the MODEL procedure of SAS/ETS Version 6.04 for IBM-compatible personal computers (SAS Institute 1988). These values, along with the FoxPro source code that implements the econometric submodels described in this report, are given in this appendix. 


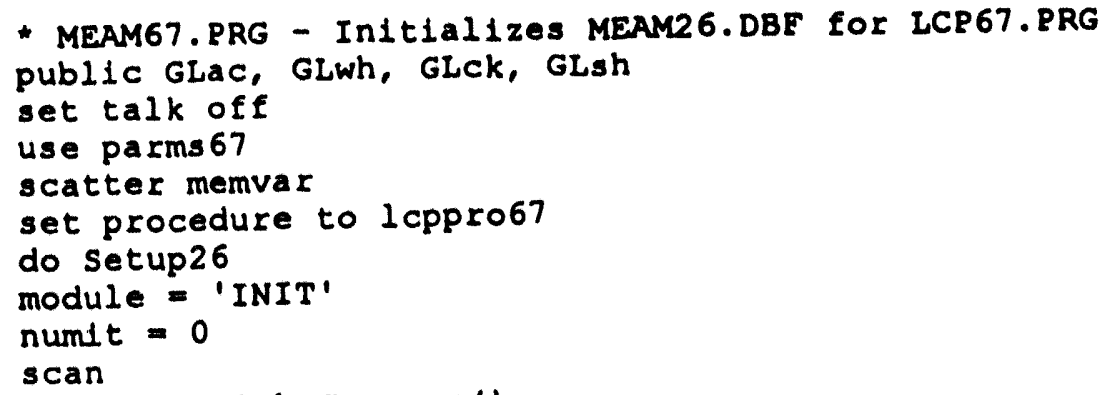


* LCPPRO67.PRG - PROCEDURE FILE FOR MEAM/LCP Version 6.7

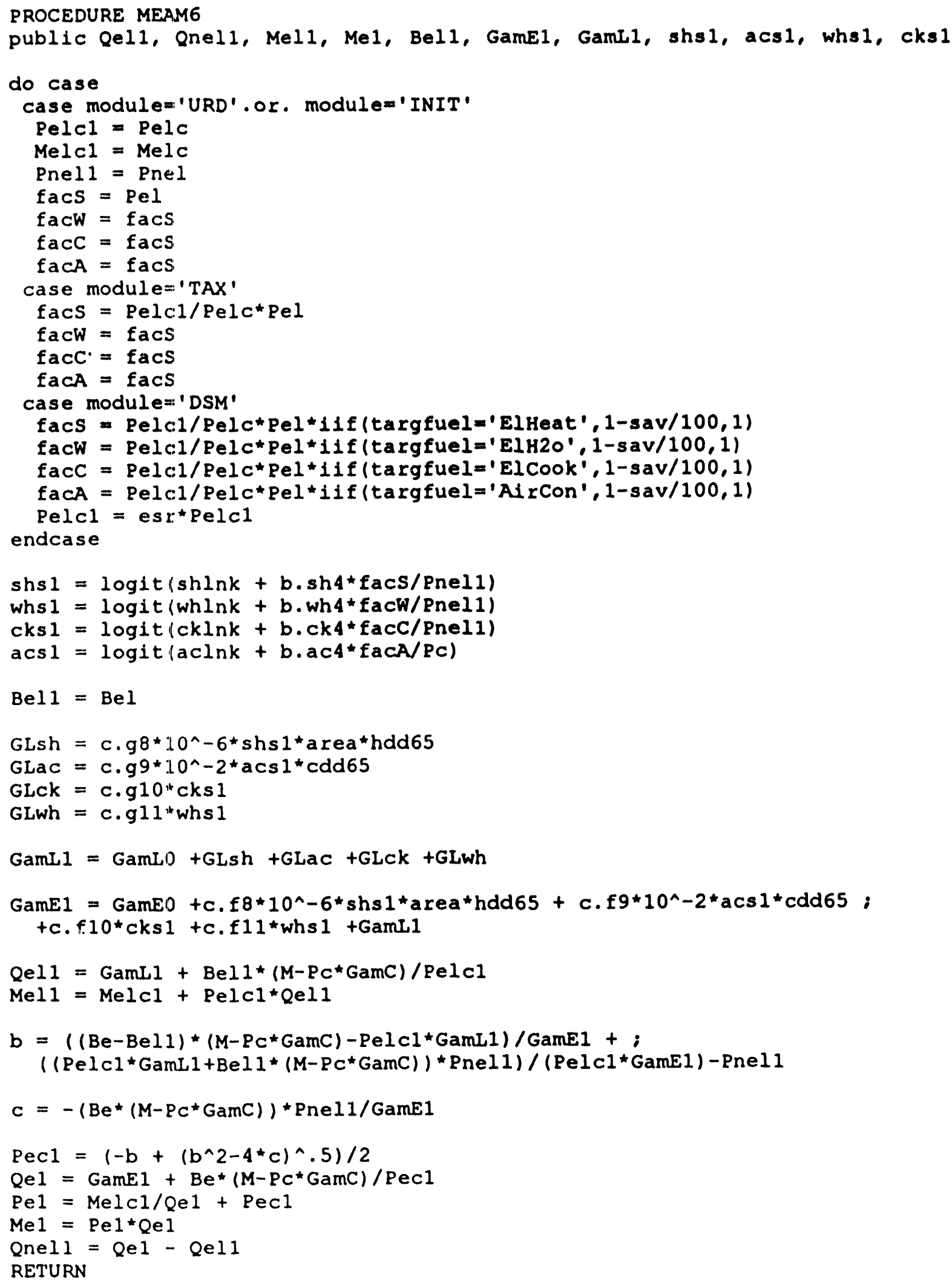


FUNCTION KWh

public _Kwh, _dKwh, Qell, Qnel1, Game1, Bel1, Me1, Pelc1, Melc1, Pnell

Pnell = Pnel

facl $=$ Pel $*$ EnChg $/$ EnChgo

shs $1=\operatorname{logit}(\operatorname{shlnk}+$ b.sh $4 *$ facl $1 /$ Pnell 1$)$

whs 1 = logit (whlnk + b.wh4*facl/Pnel1)

cks 1 = logit (cklnk + b.ck4*facl/Pnell)

acs 1 = logit (aclnk + b.ac4*facl/Pc)

Pelcl $=$ Pelc EnChg/EnChgo

Melcl $=$ Melc $+($ CusChg-CusChgo $) * 12$

- Pelcl = Pelc

*Melc1 = Melc

$\mathrm{Bell}=\mathrm{Bel}$

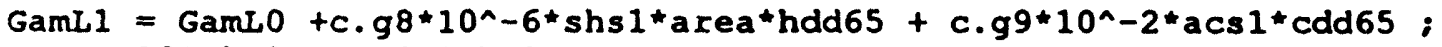
$+c . g 10^{*}$ cks 1 +c.g11*whs 1

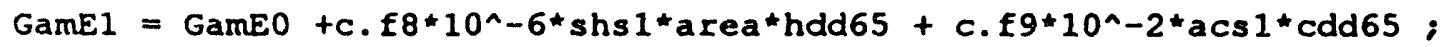
$+c . f 10^{\star}$ cks $1+c . f 11$ *wh 1 +GamL 1

Qe11 = GamL1 + Bel1*(M-PC*GamC)/Pelc1

$b=((B e-B e 11) *(M-P C *$ GamC $)-P e 1 c 1 *$ GamL1 $) /$ GamE1 + ;

$\left(\left(\right.\right.$ Pelcl $\left.{ }^{\star G a m L} 1+B e 11 *(M-P C \star G a m C)\right) \star$ Pnel 1$) /($ Pelc1*GamE1 $)-$ Pnel1

$C=-\left(B e^{\star}(M-P C *\right.$ GamC $\left.)\right) *$ Pnel $1 /$ GamE 1

Pec1 $=\left(-b+\left(b^{\wedge} 2-4^{\star} c\right)^{\wedge} .5\right) / 2$

$Q e=\operatorname{GamEl}+\mathrm{Be}^{\star}\left(\mathrm{M}-\mathrm{PC}^{\star}\right.$ GamC $) / \mathrm{PeCl}$

$\mathrm{Pe}=\mathrm{Melc1} / \mathrm{Qe}+\mathrm{Pec1}$

$\mathrm{Me} 1=\mathrm{Pe} \mathrm{Qe}^{\mathrm{N}}$

Mel1 $=$ Melcl + Pelc1*Qell

Qnell $=$ Qe - Qell

$\mathrm{dKwh}=($ Qel1-Qel $) / .00341$

Kwh $=$ Qel1/.00341

RETURN_KWh

PROCEDURE CUMPLOT

\& Writes Cum Dist of Xval to CUMPLOT.PRN

parameter graphno

declare ma (4), $\mathrm{mn}(4)$

set safety off

use cumplot

zap

append from meam26

index on xval to $t 1$

$\operatorname{cum} 1=0$

cum2 $=0$

cum3 $=0$

cum4 $=0$

sum nweight, xval*nweight to sum1, $\operatorname{mn}(1)$ for '1'sycat

sum nweight, xval*nweight to sum2, $\operatorname{mn}(2)$ for '2'sycat

sum nweight, xval*nweight to sum3, $\mathrm{mn}(3)$ for '3'sycat

sum nweight, xval*nweight to sum4, $\mathrm{mn}(4)$ for '4'sycat

6 majority

\&\& black

6 hispanic

recnum $=0$ 


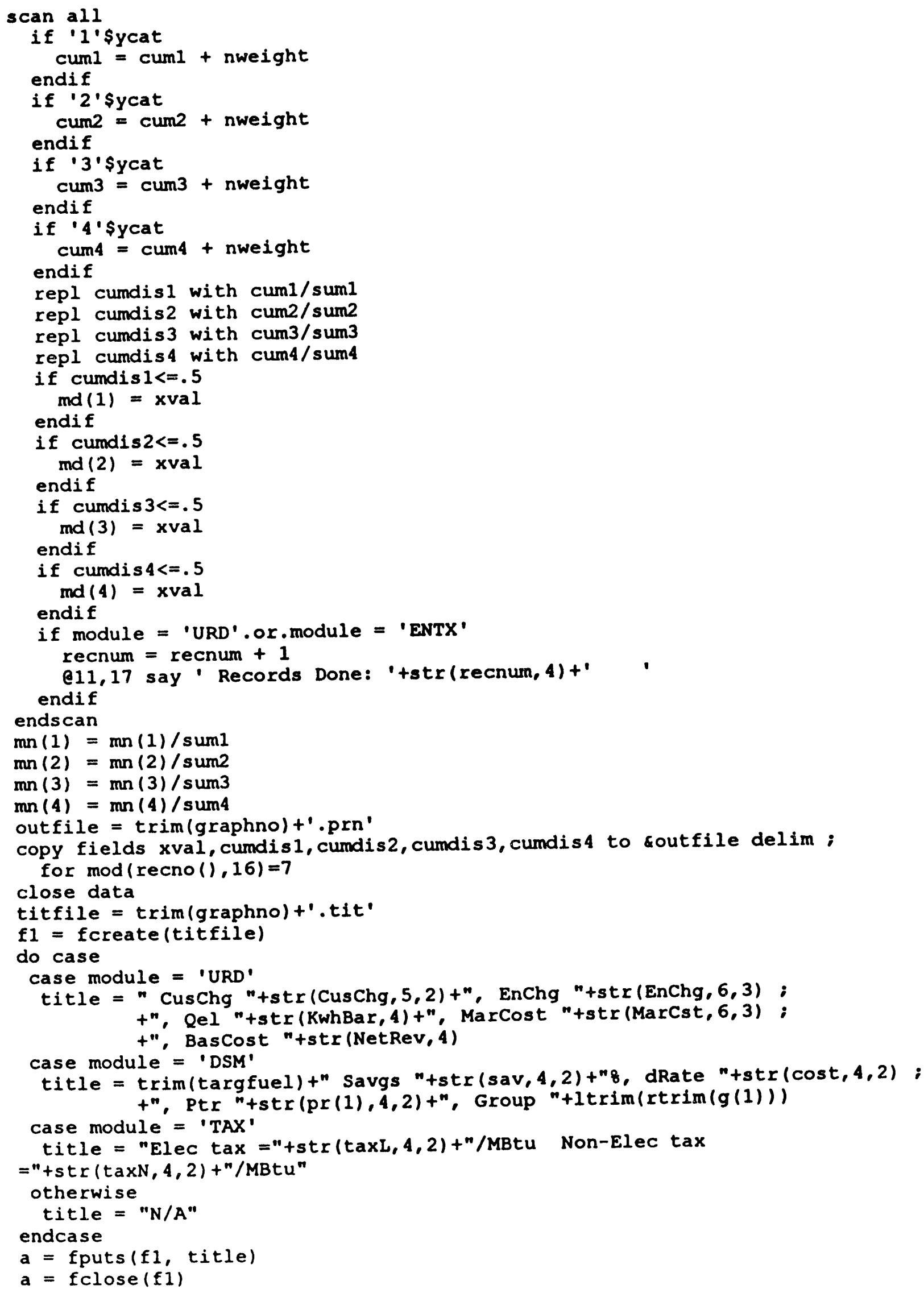




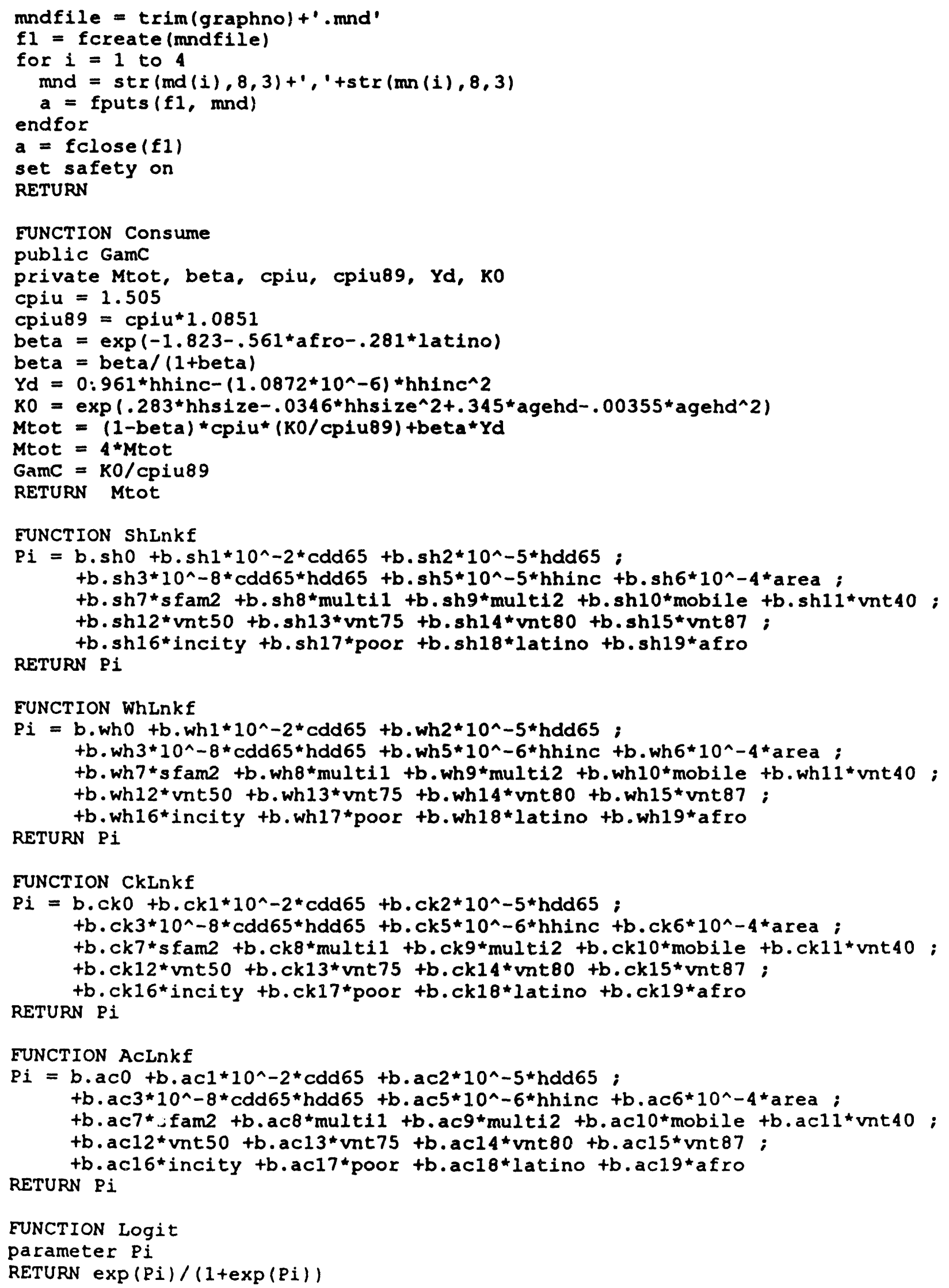




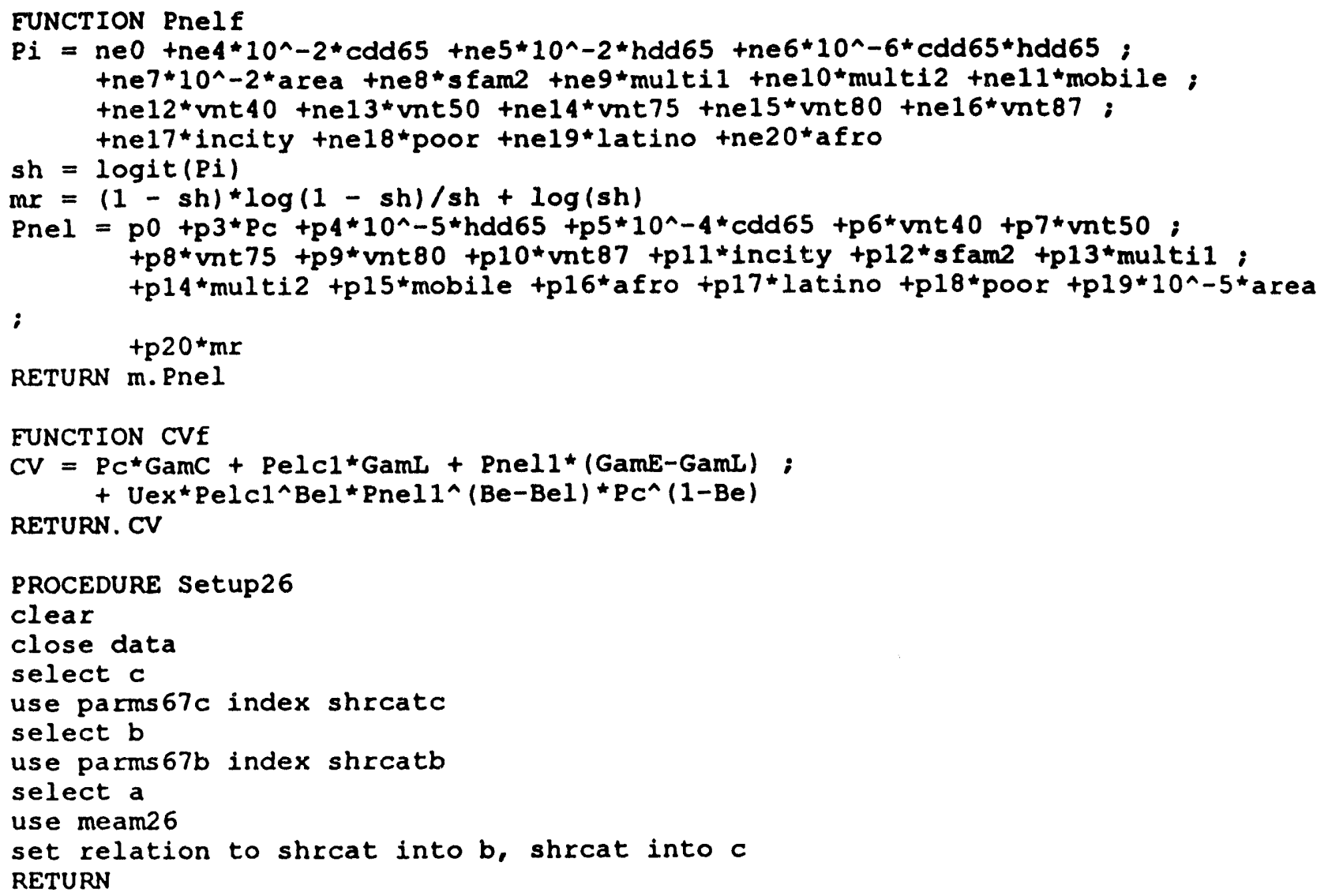




\section{EPSIM Parameters}

\section{From PARMS67.DBF}

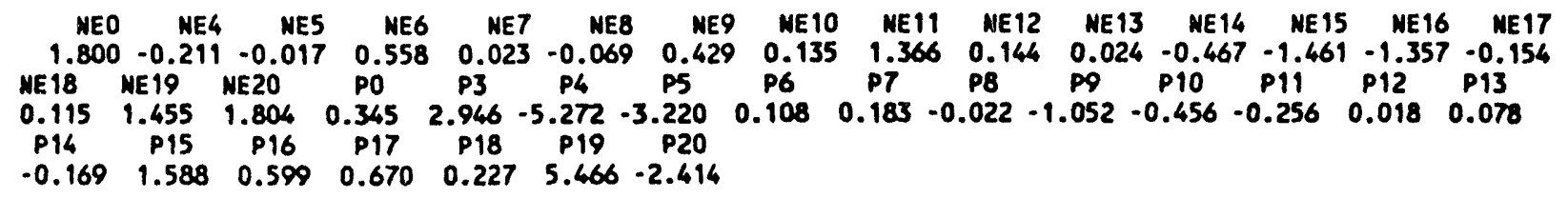

\section{From PARMS67B.DBE}

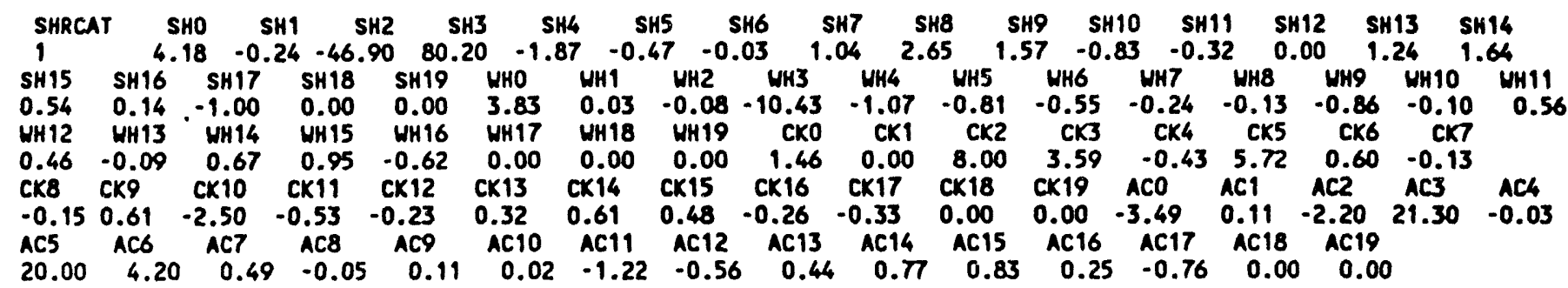

$\begin{array}{llllllllllllll}\text { SHRCAT SHO } & \text { SH1 } & \text { SH2 } & \text { SH3 } & \text { SH4 } & \text { SH5 } & \text { SH6 } & \text { SH7 } & \text { SH8 } & \text { SH9 } & \text { SH10 } & \text { SH11 } & \text { SH12 } & \text { SH13 SH14 }\end{array}$ SH15 SH16 SH17 SH18 SH19 HHO WH1 HH2 WH3 WH4 HHS WH6 WH7 HH8 WH9 WH10 UH11 $\begin{array}{llllllllllllllllllll}0.00 & 1.31 & -2.83 & 0.00 & 0.00 & 1.71 & 0.25 & 35.00 & -73.66 & -1.28 & -32.00 & 0.60 & 0.50 & -0.92 & 0.55 & 0.00 & 0.00\end{array}$ WH12 WH13 WH14 WH15 WH16 WH17 WH18 WH19 CKO CK1 CK2 CK3 CK4 CK5 CK6 CK7

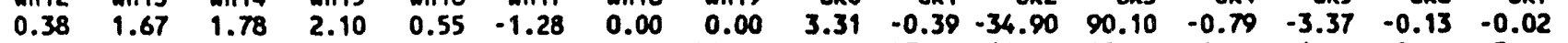
CK8 CK9 C.110 CK11 CK12 CK13 CK14 CK15 CK16 CK17 CK18 CK19 ACO AC1 AC2 AC3 AC4

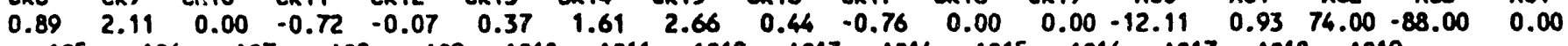

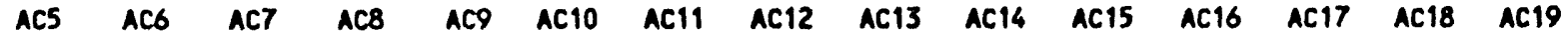

$\begin{array}{lllllllllllllll}3.22 & 1.50 & 0.56 & -1.22 & 1.57 & 0.00 & -0.98 & -0.75 & 0.98 & 1.48 & -2.13 & 0.30 & -1.55 & 0.00 & 0.00\end{array}$

From PARMS67C.DBE

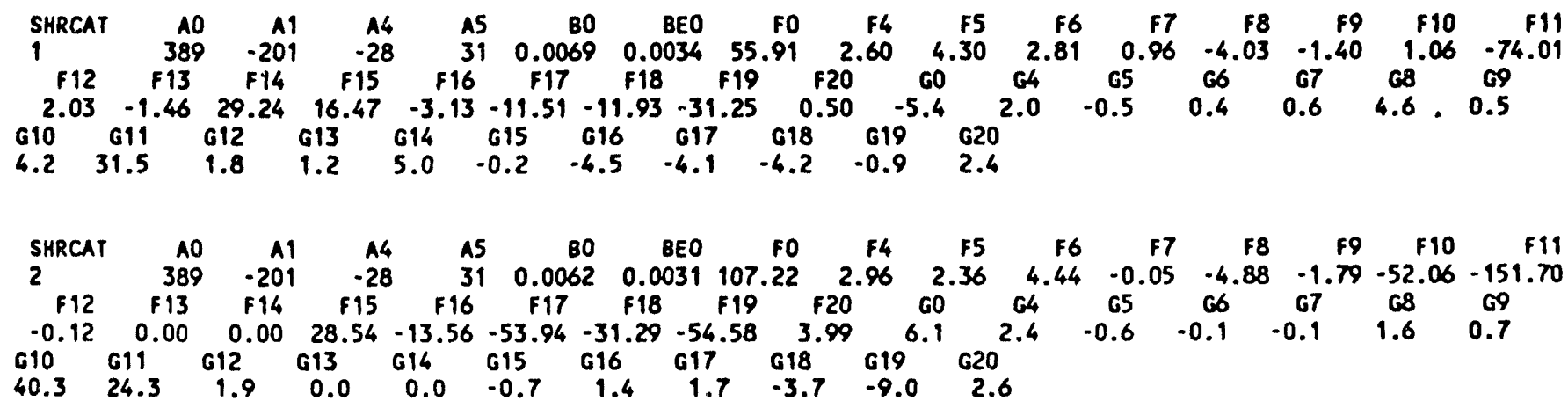



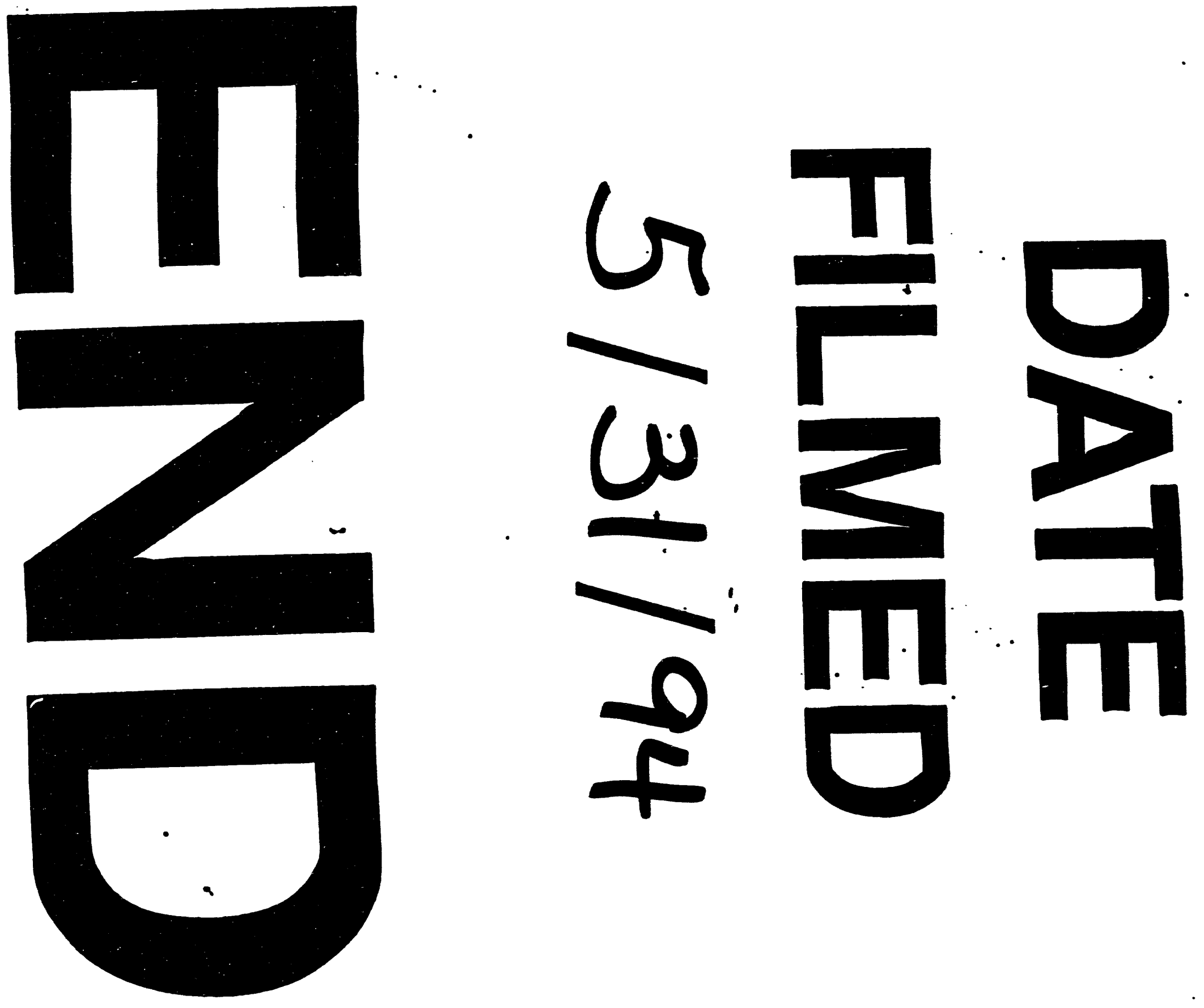
